OPEN ACCESS

Edited by:

Xiaoxiao Huang,

Shenyang Pharmaceutical University,

China

Reviewed by:

Jialin $Q u$,

Dalian Medical University, China

Tingting Zhou,

Second Military Medical University,

China

${ }^{*}$ Correspondence:

Feng Wei

weifeng@nifdc.org.cn

Shuangcheng $\mathrm{Ma}$

masc@nifdc.org.cn

Specialty section:

This article was submitted to

Organic Chemistry,

a section of the journal

Frontiers in Chemistry

Received: 29 July 2021

Accepted: 09 September 2021

Published: 30 September 2021

Citation:

Liu W, Cheng X, Kang R, Wang Y, Guo $X$, Jing W, Wei F and Ma S (2021)

Systematic Characterization and

Identification of Saikosaponins in

Extracts From Bupleurum marginatum var. stenophyllum Using UPLC-PDA-

Q/TOF-MS.

Front. Chem. 9:747987

doi: 10.3389/fchem.2021.747987

\section{Systematic Characterization and Identification of Saikosaponins in Extracts From Bupleurum marginatum var. stenophyllum Using UPLC-PDA-Q/TOF-MS}

Wenxi Liu ${ }^{1,2}$, Xianlong Cheng ${ }^{2}$, Rong Kang ${ }^{2}$, Yadan Wang ${ }^{2}$, Xiaohan Guo ${ }^{2}$, Wenguang Jing ${ }^{2}$, Feng $\mathrm{Wei}^{2 *}$ and Shuangcheng $\mathrm{Ma}^{1,2 *}$

${ }^{1}$ Chinese Academy of Medical Science and Peking Union Medical College, Beijing, China, ${ }^{2}$ National Institutes for Food and Drug Control, National Medical Products Administration, Beijing, China

Saikosaponins comprise a large group of chemical components present in the Bupleurum species that have attracted attention in the field of medicine because of their significant biological activities. Due to the high polarity, structural similarity, and the presence of several isomers of this class of components, their structural identification is extremely challenging. In this study, the mass spectrometric fragmentation pathways, UV spectral features, and chromatographic behavior of different types of saikosaponins were investigated using 24 standard substances. Saikosaponins containing carbonyl groups $(\mathrm{C}=\mathrm{O})$ in the aglycone produced fragment ions by loss of $30 \mathrm{Da}$, and in addition, type IV saikosaponins could produce [aglycone- $\left.\mathrm{CH}_{2} \mathrm{OH}-\mathrm{OH}-\mathrm{H}\right]^{-}$and [aglycone- $\left.\mathrm{H}_{2} \mathrm{O}-\mathrm{H}\right]^{-}$ fragment ions through neutral losses at positions $\mathrm{C}_{16}$ and $\mathrm{C}_{17}$. The above characteristic ions can be used to identify saikosaponins. More notably, the identification process of saikosaponins was systematically summarized, and using this method, 109 saikosaponins were identified or tentatively characterized from the saikosaponins extract of Bupleurum marginatum var. stenophyllum (BMS) using UPLCPDA-Q/TOF-MS with both data-dependent acquisition (DDA) and data-independent acquisition (DIA) modes, of which 25 were new compounds and 60 were first discovered from BMS. Further studies revealed that the saikosaponins profiles of BMS, Bupleurum chinense DC (BC), and Bupleurum marginatum Wall. ex DC (BMW) were very similar. This work is of great significance for the basic research of the Bupleurum species and provides strong technical support to solve the resource problems associated with Radix Bupleuri.

Keywords: saikosaponins, radix bupleuri, UPLC-PDA-Q/TOF-MS, Bupleurum marginatum var. stenophyllum, Bupleurum chinense DC, Bupleurum marginatum Wall. ex DC 


\section{INTRODUCTION}

Radix Bupleuri (RB) is a classic herb from the Bupleurum species called "chaihu" in Chinese. As one of the most successful and widely used traditional Chinese medicines (TCMs) in Asia, RB is widely used clinically to treat liver disease, fever, chills, tumor, hypochondria, inflammation, and uterine prolapse and has a history of over 2000 years (Ashour and Wink, 2011). According to the Chinese Pharmacopeia, Bupleurum chinense DC (BC) and Bupleurum scorzonerifolium Willd. are recognized as the official medicinal materials of RB, which are named "North Chaihu" and "South Chaihu," respectively. With the growing attention to improving health conditions, the development and utilization of $\mathrm{RB}$ resources have expanded rapidly, but actual $\mathrm{RB}$ resources have gradually decreased due to irrational harvesting and waning fields for forestry. Therefore, it is urgent to search for other Bupleurum species that can replace legal RB species as medicine for development and application.

Bupleurum marginatum var. stenophyllum (BMS) is a major Bupleurum species used in TCM in China and was first recorded in the Southern Yunnan Materia Medica. BMS was introduced from Tibet, due to its high yield, high content of saikosaponins, and low price, and it was widely planted in Gansu and other regions, gradually radiating to Shanxi, Qinghai, and other provinces across China. BMS is an abundant resource and has a long history of medicinal use; related studies have shown that the pharmacological effects of BMS are similar to those of $\mathrm{BC}$ (Wang et al., 2019; Wang et al., 2020), and the active ingredients are relatively similar to those of BC (Wang and Liu., 2019), so BMS is considered to be the preferred alternative Bupleurum species of BC with good development and application prospects. Thus, it is necessary to conduct detailed basic research on its main active ingredients, the saikosaponins.

Saikosaponins are the most important pharmacochemical components of the Bupleurum species with multiple pharmacological activities that cover nearly all aspects of the medicinal efficacy of Bupleurum medicinal materials (Abe et al., 1982; Zhao et al., 2019; Ren et al., 2019; Wang et al., 2013; Li et al., 2018). There are a large variety of saikosaponins, and to date, over 100 saikosaponins have been isolated from the Bupleurum species, and their structures are mainly pentacyclic triterpenoid derivatives, which have mainly been classified into 7 different types based on the aglycone structure: epoxy ether at $\mathrm{C}_{13}, \mathrm{C}_{28}$-position (type I), isocyclic diene (type II), $\mathrm{C}_{12}$-ene (type III), homocyclic diene (type IV), $\mathrm{C}_{12}$-ene- $\mathrm{C}_{28}$-carboxylic acid (type $\mathrm{V}$ ), isocyclic diene and $\mathrm{C}_{30}$-carboxylic acid (type $\mathrm{VI}$ ), and $\mathrm{C}_{18}$-ene (type VII); the main structural formulas are shown in Figure 1. The conjugated sugars are mainly glucose (Glu), rhamnose (Rha), furanose (Fuc), xylose (Xyl), and pentitol. Saccharide chains are usually attached to the aglycone at position $\mathrm{C}_{3}$, among which type I saikosaponins only exist in Bupleurum plants and consist of the highest content of native saikosaponins in the Bupleurum species (Sun et al., 2019; Jiang et al., 2020).

Saikosaponins are not only diverse in structure but also very similar in polarity, and there are many isomers. It is tedious to purify, separate, and identify them using conventional phytochemical separation methods, and the experimental period is long. In recent years, ultra-performance liquid chromatography-mass spectrometry (UPLC-MS) has been widely used in many research fields due to its ability to obtain abundant sample information and efficient component separation, such as rapid identification of chemical components of TCM and drug quality control, speculated by aligning MS information and fragmentation patterns of target compounds with chemical standard substances or literature; the chemical components of TCM can be rapidly and accurately identified (Guo et al., 2016; Qing et al., 2017; Münger et al., 2018; Yang et al., 2019; Ye et al., 2019; Xia et al., 2021). At present, there are still many saikosaponins with structural diversity present at low abundance that remain to be separated and identified by UPLC-MS.

In this study, an efficient sample-processing method was established to extract, purify, and enrich saikosaponins, especially trace saikosaponins at low abundance; we eliminated the interference of non-saikosaponin components and improved their detection efficiency and selectivity. Next, we established an UPLC-PDA-Q/TOF-MS method combined with both DDA and DIA modes to analyze 24 different saikosaponin standard substances with known structures, fully analyzed and summarized their properties such as fragment ions, retention time, and maximum UV wavelength, further applied its summary rules to reliably characterize and identify the total saikosaponin extract from BMS, and compared them with saikosaponins of two other commonly used Bupleurum species-BC (the legal RB) and Bupleurum marginatum Wall. ex DC (BMW, another major Bupleurum species, whose genetic relationship is close to BMS); the objective was to explore the similarities and differences of saikosaponins between BMS and them in order to provide essential data for related research.

\section{MATERIALS AND METHODS}

\section{Chemicals and Reagents}

Formic acid (LC-MS grade), leucine enkephalin (LC-MS grade), and sodium formate (LC-MS grade) were obtained from SigmaAldrich Corporation (MO, United States). Methanol (LC-MS grade), acetonitrile (LC-MS grade), and ammonium acetate (LCMS grade) were obtained from Fisher Corporation (United States). Ultra-high-purity water was obtained from a Millipore Alpha-Q water purification instrument. The filter membrane $(0.22 \mu \mathrm{m})$ was obtained from Millipore Corporation (MA, United States).

Saikosaponin a (SSa, batch number 110777-201912) and Saikosaponin d (SSd, batch number 110778-201912) were purchased from China National Institutes for Food and Drug Control. Saikosaponin $\mathrm{b}_{1} \quad \mathrm{SSb}_{1}$, batch number 58558-08-0), Saikosaponin $\mathrm{b}_{2}\left(\mathrm{SSb}_{2}\right.$, batch number 58316-41-9), Saikosaponin $\mathrm{b}_{3}\left(\mathrm{SSb}_{3}\right.$, batch number 58316-42-0), Saikosaponin $\mathrm{b}_{4}\left(\mathrm{SSb}_{4}\right.$, batch number 58558-09-1), Saikosaponin c (SSc, batch number 2073608-7), Saikosaponin e (SSe, batch number 64340-44-9), Saikosaponin f (SSf, batch number 62687-63-2), 11aMethoxysaikosaponin f (11a-methoxyl-SSf, batch number 104109-37-7), Saikosaponin g (SSg, batch number 99365-19-2), 


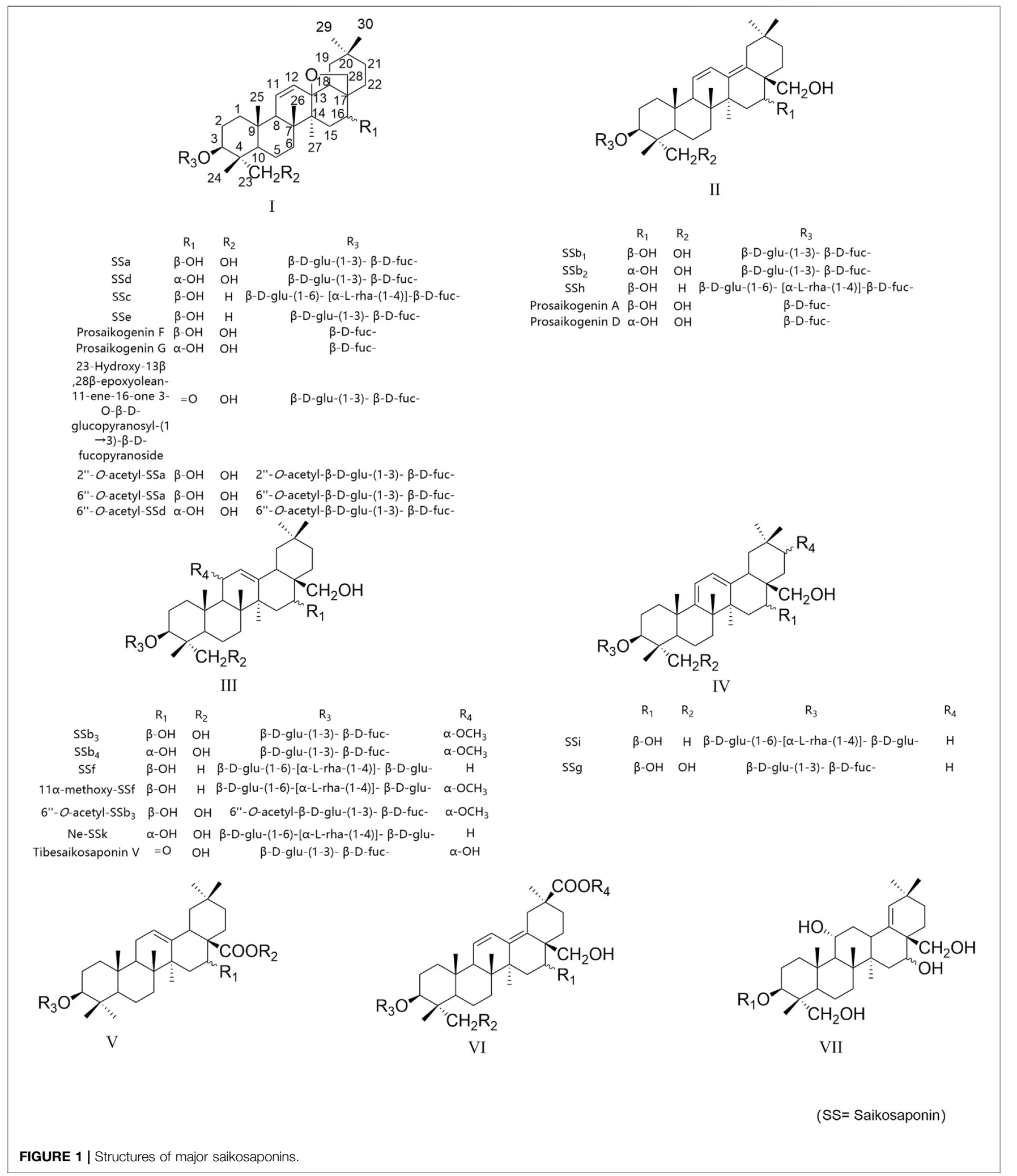

Saikosaponin h (SSh, batch number 91990-63-5), Saikosaponin i (SSi, batch number 103629-71-6), Nepasaikosaponin k (Ne-SSk, batch number 405229-61-0), Prosaikogenin d (batch number
103629-72-7), and 23-Hydroxy-13 $\beta, 28 \beta$-epoxyolean-11-ene-16one 3 -O- $\beta$-D-glucopyranosyl- $(1 \rightarrow 3)-\beta$-D-fucopyranoside (batch number 106452-32-8) were purchased from Shanghai Standard 
Technology Co., Ltd. (Shanghai, China). 6"-OAcetylsaikosaponin- $\mathrm{SSb}_{3} \quad\left(6^{\prime \prime}\right.$-O-acetyl-SSb${ }_{3}$, batch number 104109-34-4) and 6"-O-Acetylsaikosaponin a (6"-O-acetyl-SSa, batch number 64340-46-1) were purchased from Shanghai Yuanye Bio-Technology Co., Ltd. (Shanghai, China). Prosaikogenin a (batch number 99365-21-6), Prosaikogenin $f$ (batch number 99365-20-5), and Prosaikogenin g (batch number 99365-23-8) were purchased from Chengdu Pufei De Biotech Co., Ltd. (Sichuan, China). Tibesaikosaponin V (batch number 231966887-5) was purchased from Chengdu Must Biotech Co., Ltd. (Sichuang, China). 6"-O-Acetylsaikosaponin d (6"-O-acetyl-SSd, batch number 64340-45-0) and 2"-O-Acetylsaikosaponin a (2"$O$-acetyl-SSa, batch number 102934-42-9) were purchased from Chengdu Weikeqi Biotech Co., Ltd. (Sichuang, China).

The Chinese herbal BMS materials were collected from Gansu Province (China), BC materials were collected from Shanxi Province (China), and BMW materials were collected from Sichuan Province (China). The above samples were confirmed by researcher Xianlong Cheng from China National Institutes for Food and Drug Control.

\section{Preparation of the Total Saikosaponin Extract From Samples}

The samples were pulverized and extracted with 10 times the volume in $70 \%$ ethanol (containing $0.05 \%$ ammonia water) twice for $4 \mathrm{~h}$ under reflux, followed by concentration under reduced pressure. The residue was extracted with petroleum ether, ethyl acetate, and water-saturated n-butanol, respectively; the watersaturated n-butanol part was recovered to extract. We dispersed the above extract by D101 macroporous resin column chromatography, eluting with water, $30 \%$ ethanol, $70 \%$ ethanol, and 95\% ethanol in turn, and finally collected the $70 \%$ ethanol fraction to obtain the purified and enriched total saikosaponin extract of samples.

\section{Preparation of Sample Solutions and Standard Substance Solutions}

To obtain $20 \mathrm{mg}$ of the prepared total saikosaponin extract, the materials were accurately weighed and added to a $10-\mathrm{ml}$ brown volumetric flask, and methanol was added on a scale, sealed, and ice-bath sonicated for $5 \mathrm{~min}$, and the solution was filtered using a $0.22-\mu \mathrm{m}$ microporous filter membrane to obtain the sample solutions. The appropriate amount of each standard substance was weighed accurately and diluted with methanol to the desired concentrations, and the standard substance solutions were obtained.

\section{UPLC-PDA-Q/TOF-MS Analysis for Saikosaponin Extract and Standard Substance Solutions}

We used the ultra-high performance LC System with a Q/TOFMS, PDA detector, and Masslynx workstation (Waters MS Technologies, Manchester, United Kingdom) to acquire UPLC-high-resolution mass spectrometry (HRMS) raw data.
Chromatographic separation was performed on an ACQUITY BEH $\mathrm{C}_{18}$ column $(150 \mathrm{~mm} \times 2.1 \mathrm{~mm}, 1.7 \mu \mathrm{m})$, maintained at $35^{\circ} \mathrm{C}$. The flow rate was $0.3 \mathrm{ml} / \mathrm{min}$, and the injection volume was $2 \mu \mathrm{L}$. The mobile phase consisted of (solvent A) $0.05 \%$ formic acid in acetonitrile (v/v) and (solvent B) $0.05 \%$ formic acid in water (v/ $\mathrm{v})$, and the gradient elution was as follows: $0-4 \mathrm{~min}, 5 \%-15 \% \mathrm{~A}$; 4-20 min, $15 \%-30 \%$ A; $20-30$ min, 30\% A; 30-40 min, 30\%-44\% A; $40-47 \mathrm{~min}, 44 \% \mathrm{~A} ; 47-54 \mathrm{~min}, 44 \%-90 \%$ A; $54-55 \mathrm{~min}$, 90\%-98\% A; 55-56 min, 98\% A. The detection wavelength range of the PDA detector was set to $200-400 \mathrm{~nm}$.

For MS conditions, the temperature of the electrospray ion (ESI) source was set to $120^{\circ} \mathrm{C}$; the cone and capillary voltages were $30 \mathrm{~V}$ and $3.0 \mathrm{kV}$, respectively. High-purity nitrogen was selected as the desolvation gas with the desolvation temperature set to $450^{\circ} \mathrm{C}$; high-purity argon was selected as the collision gas. The $[\mathrm{M}-\mathrm{H}]^{-}$ion of leucine enkephalin (LE) at $\mathrm{m} / \mathrm{z} 554.2615$ was selected as the lock mass in $\mathrm{ESI}^{-}$; the $[\mathrm{M}+\mathrm{H}]^{+}$ion of LE at $\mathrm{m} / \mathrm{z}$ 556.2771 was selected as the lock mass in $\mathrm{ESI}^{+}$. Sodium formate solution was mass-spectrometrically tuned to ensure the accuracy and reproducibility during the experiment. For the data acquisition mode, the $\mathrm{MS}^{\mathrm{E}}$ and DDA acquisition modes were selected, and the mass scan range was 100-1,500 Da. In the $\mathrm{MS}^{\mathrm{E}}$ continuous acquisition mode, the sample data were collected by setting high and low two different collision energy (CE) pathways alternately to obtain molecular ions and fragment ions of target compounds. In terms of the $\mathrm{CE}$, the low $\mathrm{CE}$ channel was set to $8 \mathrm{~V}$ and the high $\mathrm{CE}$ channel was set to $20-70 \mathrm{~V}$. The DDA acquisition mode was set to 5 ion acquisition channels, and other acquisition conditions were the same as the $\mathrm{MS}^{\mathrm{E}}$ mode.

\section{RESULTS AND DISCUSSION}

\section{Establishment of Sample-Processing Method}

Conventional sample-processing methods mostly use methanol to extract saikosaponins for detection, which presents shortcomings. First, numerous non-saikosaponin components present in the extraction solution, which are extracted together with saikosaponins during detection, interfere with the identification of saikosaponins. Second, the extraction efficiency is low, and many trace saikosaponins are not fully extracted, which results in the missed detection. In this study, an efficient sample-processing method was developed to extract, enrich, and purify saikosaponins (especially the trace saikosaponins), eliminate the interference of non-saikosaponin components, and improve their detection efficiency and selectivity.

\section{Establishment of Detection Method}

The range of UV detection wavelengths was set at $200-400 \mathrm{~nm}$ based on the structure of the saikosaponins. The data acquisition modes of mass spectrometry included data-dependent acquisition (DDA) and data-independent acquisition (DIA, i.e., $\mathrm{MS}^{\mathrm{E}}$ ). The DDA mode reduces the existence of interfering ions because it uses a narrow $\mathrm{m} / \mathrm{z}$ window to screen target ions. Therefore, it can provide high-quality fragment information, but 
when valuable ions cannot satisfy the target screening conditions or co-flow with high-intensity ions, these target ions cannot be selected for fragmentation, or the number of parent ions selected will be too large, and this will lead to insufficient acquisition of the total ion chromatograms or base peak ion chromatograms (BPI) of the primary mass spectrum. For the DIA $\left(\mathrm{MS}^{\mathrm{E}}\right)$ mode, the primary mass spectrum of ions was obtained at the low $\mathrm{CE}$ channel, and fragment ion information was obtained at the $\mathrm{CE}$ channel. In theory, the fragment information of all ions can be obtained comprehensively without screening the parent ions in advance. However, if there are many ions flowing concurrently, it is difficult to directly analyze the primary mass spectra and fragment ions, that is, it is difficult to directly determine from which specific parent the fragment ions in the secondary mass spectrum (MS/MS) derive (Law and Lim, 2013; Bateman et al., 2014).

Because saikosaponin compounds present both structural diversity and high structural similarity, even under gradient elution, it is currently difficult to separate all saikosaponin compounds from the baseline completely, in which there are co-efflux components and many trace saikosaponins with a low response. Thus, we combined the DDA and DIA $\left(\mathrm{MS}^{\mathrm{E}}\right)$ modes to complement each other to scan and analyze parent ions and product fragment ions of saikosaponins accurately and comprehensively. The $\mathrm{ESI}^{-}$mode provides more abundant structural information of saikosaponin compounds, while the $\mathrm{ESI}^{+}$spectra of saikosaponins provide less information and compounds are subjected to breakage in the low CE scanning channel, which results in more interference with the analysis but can also document the characteristic fragment ions in $\mathrm{ESI}^{+}$and contribute to the determination of the specific position of substituent groups in acetylated/malonylated saikosaponins (Liu et al., 2019). Thus, this approach was used to identify saikosaponins in the $\mathrm{ESI}^{-}$, whereas for the identified acetylated/malonylated saikosaponins in $\mathrm{ESI}^{-}$, their fragment ions in $\mathrm{ESI}^{+}$were combined to speculate on the specific position of the respective acetyl/malonyl groups.

\section{UPLC-PDA-Q/TOF-MS Analysis of Saikosaponin Standard Substances}

In this study, fragment ions were named according to the nomenclature rules of Domon and Costello (Supplementary Figure S1) (Domon and Costello, 1988). A total of 24 saikosaponin standard substances (classified as types I-IV according to their aglycone structures and their acetylated derivatives were classified separately as one group for analysis) were subjected to analysis and the information obtained regarding the chromatographic, fragmentation behavior and maximum UV wavelength was summarized, their structures are shown in Figure 1, and chromatography, UV absorption, and MS spectrum details for each standard substance are shown in Supplementary Table S1.

\section{Analysis of Type I Saikosaponins}

$\mathrm{SSa}\left(\beta-\mathrm{OH}\right.$ at position $\left.\mathrm{C}_{16}\right)$ and $\mathrm{SSd}\left(\alpha-\mathrm{OH}\right.$ at position $\left.\mathrm{C}_{16}\right)$ were a pair of epimers, with the same molecular ion $\left([\mathrm{M}-\mathrm{H}]^{-}\right)$at $\mathrm{m} / \mathrm{z}$
779; their fragmentation behaviors were similar. In the $\mathrm{ESI}^{-}$mode, the fragment ions of the MS/MS spectrum (Supplementary Table S1) were analyzed, and the $Y_{1}(\mathrm{~m} / \mathrm{z} 617)$ ion corresponding to the $[\mathrm{M}-\mathrm{H}]^{-}$lost a fragment of $162 \mathrm{Da}$, indicating that a glucosyl group (Glu, $162 \mathrm{Da}, \mathrm{C}_{6} \mathrm{H}_{10} \mathrm{O}_{5}$ ) at the end of the saccharide chain was lost. The $\mathrm{X}_{0}(\mathrm{~m} / \mathrm{z} 541)$ ion was produced by the breakage of the $Y_{1}\left(\mathrm{~m} / \mathrm{z}\right.$ 617) ion, corresponding to the $\mathrm{Y}_{1}$ ion with a lost fragment of $76 \mathrm{Da}\left(\mathrm{C}_{3} \mathrm{H}_{8} \mathrm{O}_{2}\right)$, which represented the intracyclic breakage of furanose $\left(0,3\right.$-bond breakage). The $\left[\mathrm{Y}_{1}-76-\mathrm{H}\right]^{-}(\mathrm{m} / \mathrm{z}$ 541) fragment ion was produced when the furanose (Fuc, $146 \mathrm{Da}$, $\mathrm{C}_{6} \mathrm{H}_{10} \mathrm{O}_{4}$ ) was directly attached to the aglycone in the structure of saikosaponins; conversely, the presence of the $\left[\mathrm{Y}_{1}-76-\mathrm{H}\right]^{-}$ fragment ion was not detected for saikosaponins without furanose. Thus, a fragment of $76 \mathrm{Da}\left(\mathrm{C}_{3} \mathrm{H}_{8} \mathrm{O}_{2}\right)$ was lost as the specific fragmentation pathway of furanose, which was consistent with previous reports (Huang et al., 2008). Among the characteristic fragment ions of SSa/SSd was $\mathrm{m} / \mathrm{z} \quad 471$ $\left([\mathrm{M}-\mathrm{Glu}-\mathrm{Fuc}-\mathrm{H}]^{-}\right)$, which corresponded to the molecular ion without the complete saccharide chain and corresponded to the sapogenin ion $\left([\text { aglycone- } \mathrm{H}]^{-}\right)$; the $[\text {aglycone }-\mathrm{H}]^{-}$lost a fragment of $32 \mathrm{Da}$ to produce the $\mathrm{m} / \mathrm{z} 439$ ([aglycone- $\left.\mathrm{CH}_{3} \mathrm{OH}-\mathrm{H}\right]^{-}$) fragment ion, corresponding to the aglycone with the loss of one molecule of $\mathrm{CH}_{3} \mathrm{OH}$ at position $\mathrm{C}_{4}$, which was consistent with the available literature (Zhao et al., 1996). The fragmentation pathway of SSa/SSd is shown in Figure 2A. Similarly, the fragmentation pathways of SSe, Prosaikogenin f, Prosaikogenin g, and other type I saikosaponins are similar to those of SSa/SSd. For SSc, the aglycone structure is different from that of SSa; the group at position $\mathrm{C}_{23}$ is methyl $\left(\mathrm{CH}_{3}\right)$, and its fragmentation pathway is shown in Figure 2B.

23 -Hydroxy-13 $\beta, 28 \beta$-epoxyolean-11-ene-16-one 3-O- $\beta$-Dglucopyranosyl- $(1 \rightarrow 3)-\beta$-D-fucopyranoside presents a carbonyl group $(\mathrm{C}=\mathrm{O})$ in the aglycone moiety and its characteristic fragment ions appeared at $\mathrm{m} / \mathrm{z} \quad 407$ ([aglycone- $\left.\mathrm{CH}_{3} \mathrm{OH}-30-\mathrm{H}\right]^{-}$) in the $\mathrm{ESI}^{-}$mode, corresponding to the $[\text { aglycone- } \mathrm{H}]^{-}$, and lost a fragment of $30 \mathrm{Da}$. It was speculated that the $\mathrm{C}_{13}, \mathrm{C}_{28}$-epoxy ether bond was broken first and was followed by a rearrangement reaction of the $\mathrm{C}=\mathrm{O}$ group at the $\mathrm{C}_{16}$ position and breakage. The fragmentation pathway is shown in Supplementary Figure S2.

Retention times of type I saikosaponins showed (Supplementary Table S1) that for a pair of epimers, the retention time of $\beta-\mathrm{OH}$ at position $\mathrm{C}_{16}$ was earlier than that of the $\alpha-\mathrm{OH}$ epimer (such as SSa/SSd and Prosaikogenin g/Prosaikogenin f). For the type I saikosaponins, their aglycones present only one double bond (no conjugation), so their maximum UV wavelengths were generally around at the terminal ends (190-220 $\mathrm{nm}$ ); the representative UV spectra are shown in Figure 8A.

\section{Analysis of Type II Saikosaponins}

Epimers $\mathrm{SSb}_{1}\left(\beta-\mathrm{OH}\right.$ at position $\left.\mathrm{C}_{16}\right)$ and $\mathrm{SSb}_{2}(\alpha-\mathrm{OH}$ at position $\mathrm{C}_{16}$ ) are converted from SSa and SSd, respectively. In the $\mathrm{ESI}^{-}$mode, the fragmentation behavior of the two epimers was similar to that of SSa/SSd, and they also produced the following fragment ions: $\mathrm{m} / \mathrm{z} \quad 617 \quad\left([\mathrm{M}-\mathrm{Glu}-\mathrm{H}]^{-}\right), \quad \mathrm{m} / \mathrm{z} \quad 541$ 


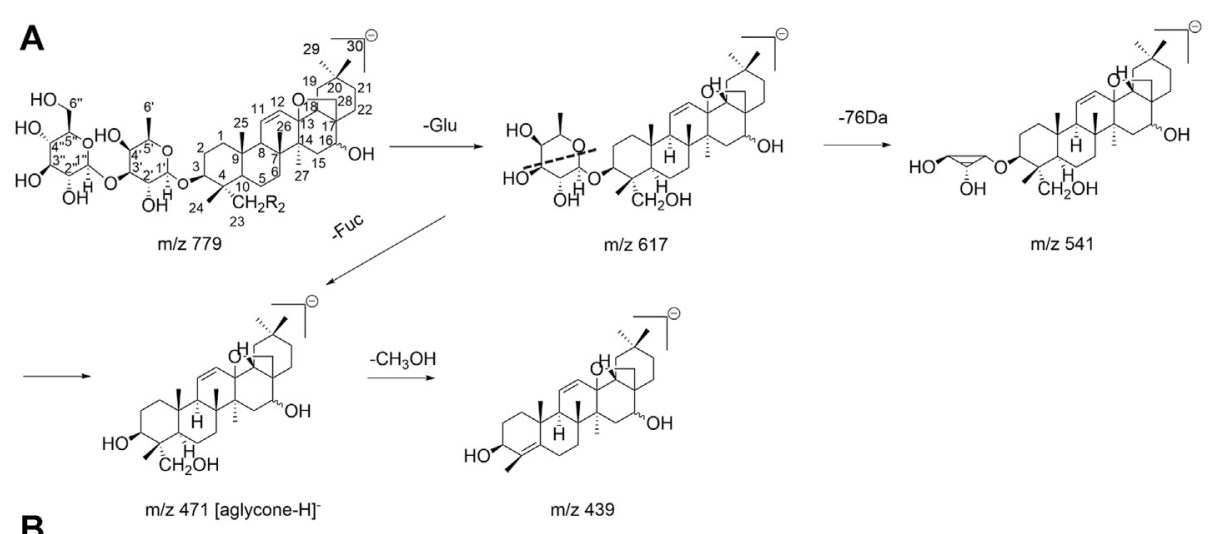

в

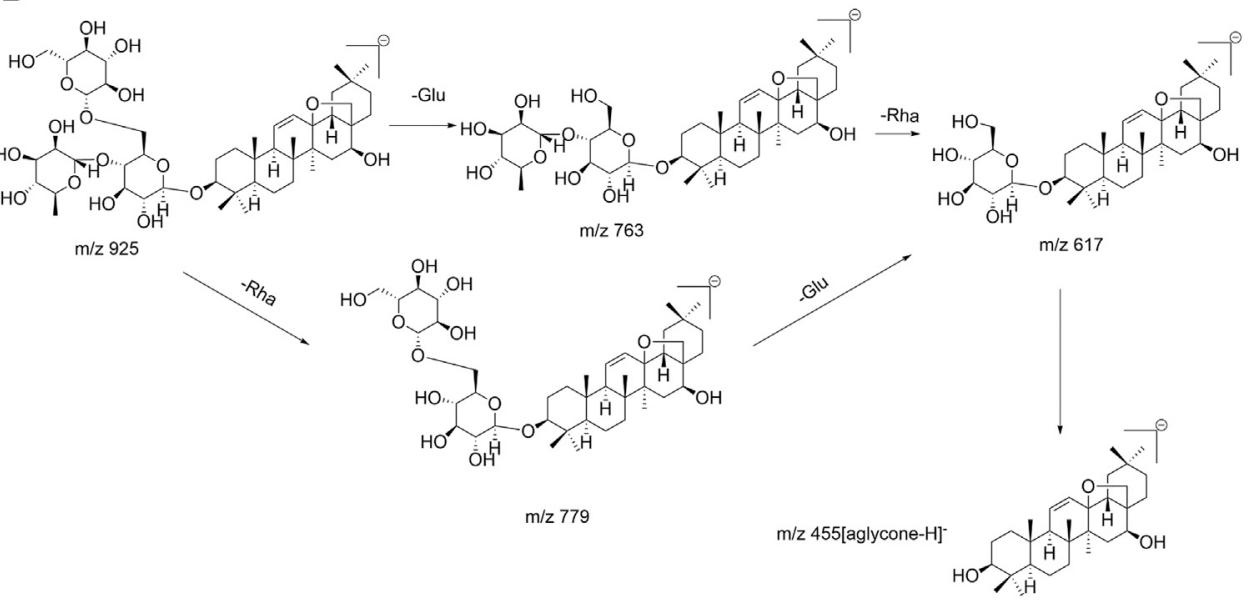

FIGURE 2 | Fragmentation pathway of (A) SSa/d and (B) SSc.

$\left(\left[\mathrm{M}-\mathrm{Glu}-\mathrm{C}_{3} \mathrm{H}_{8} \mathrm{O}_{2}-\mathrm{H}\right]^{-}\right), \quad \mathrm{m} / \mathrm{z} \quad 471 \quad\left([\mathrm{M}-\mathrm{Glu}-\mathrm{Fuc}-\mathrm{H}]^{-}\right.$, corresponding to [aglycone- $\mathrm{H}]^{-}$), and $\mathrm{m} / \mathrm{z} 439$ ([aglycone- $\left.\mathrm{CH}_{3} \mathrm{OH}-\mathrm{H}\right]^{-}$). Compared with $\mathrm{SSa} / \mathrm{SSd}$ (type I), $\mathrm{SSb}_{1} / \mathrm{SSb}_{2}$ lost a $\mathrm{CH}_{2} \mathrm{OH}$ group at position $\mathrm{C}_{17}$ and a hydroxyl $(\mathrm{OH})$ group at position $\mathrm{C}_{16}$ in the aglycone, simultaneously, and generated the $\mathrm{m} / \mathrm{z} 423$ ([aglycone-48- $]^{-}$) fragment ion, which was consistent with the fragmentation behavior found by Liu et al. (Liu et al., 2019). Because SSf presented a single double bond of aglycone and did not produce a m/z 409 ([aglycone-48-H $]^{-}$) fragment ion, it can be inferred that this fragmentation pathway only occurred when two double bonds were conjugated. Interestingly, it was worth noting that this experiment found that the abundance of $\mathrm{m} / \mathrm{z} 423$ ([aglycone- $\left.\mathrm{CH}_{2} \mathrm{OH}-\mathrm{OH}-\mathrm{H}\right]^{-}$) fragment ion produced by $\mathrm{SSb}_{1}$ having the $\beta-\mathrm{OH}$ at the $\mathrm{C}_{16}$ position was greater than that of the $\mathrm{m} / \mathrm{z} 439$ ([aglycone- $\left.\mathrm{CH}_{3} \mathrm{OH}-\mathrm{H}\right]^{-}$) fragment ion, while the abundance of the $\mathrm{m} / \mathrm{z} 423$ fragment ion produced by the $\mathrm{SSb}_{2}$ with the a-OH at position $\mathrm{C}_{16}$ was lower than that of the $\mathrm{m} / \mathrm{z} 439$ fragment ion produced. As shown in Supplementary Figure S3, it is helpful to distinguish between the same pair of epimers in type II saikosaponin. These rules and findings were also applicable to other type II saikosaponins such as Prosaikogenin a, Prosaikogenin d, SSh, etc. The fragmentation pathway of $\mathrm{SSb}_{1} / \mathrm{SSb}_{2}$ is shown in Figure 3. The fragmentation pathway of $\mathrm{SSh}$ (the group at the $\mathrm{C}_{23}$ position is $\mathrm{CH}_{3}$ ) is shown in Supplementary Figure S4 and also produced a m/z 407 ([aglycone- $\left.\mathrm{CH}_{2} \mathrm{OH}-\mathrm{OH}-\mathrm{H}\right]^{-}$) fragment ion. Thus, the [aglycone $-48-\mathrm{H}]^{-}$could be considered diagnostic fragment ions of type II saikosaponins, while the loss of $48 \mathrm{Da}$ (neutral loss of $\mathrm{CH}_{2} \mathrm{OH}$ and $\mathrm{OH}$ groups) may also be considered a characteristic loss of type II saikosaponins.

Retention times of type II saikosaponins are reported in Supplementary Table S1. For the pair of epimers, the retention time of $\beta-\mathrm{OH}$ at the $\mathrm{C}_{16}$ position was later than that of the $\mathrm{a}-\mathrm{OH}$ epimer (such as $\mathrm{SSb}_{1} / \mathrm{SSb}_{2}$ and Prosaikogenin a/Prosaikogenin $d$ ), which was contrary to that of type I saikosaponins. For the type II saikosaponins, the aglycones presented two double bonds (isocyclic diene conjugation), and the maximum UV wavelengths were generally around $250 \mathrm{~nm}$; the representative UV spectra are shown in Figure 8B.

\section{Analysis of Type III Saikosaponins}

$\mathrm{SSb}_{3}\left(\beta-\mathrm{OH}\right.$ at position $\left.\mathrm{C}_{16}\right)$ and $\mathrm{SSb}_{4}\left(\alpha-\mathrm{OH}\right.$ at position $\left.\mathrm{C}_{16}\right)$ with the aglycone structure of $\mathrm{C}_{11}-\mathrm{OCH}_{3}$ are epimers. According to the fragment ions produced in the $\mathrm{ESI}^{-}$mode, the aglycone was released at the $\mathrm{C}_{11}$ position, one molecule of $\mathrm{CH}_{3} \mathrm{OH}(32 \mathrm{Da})$ was lost and produced an aglycone with $\mathrm{C}_{8}-\mathrm{C}_{11}$ double bonds, and the $\mathrm{m} / \mathrm{z} 471$ ([aglycone- $\left.\mathrm{CH}_{3} \mathrm{OH}-\mathrm{H}\right]^{-}$) fragment ion was produced. 


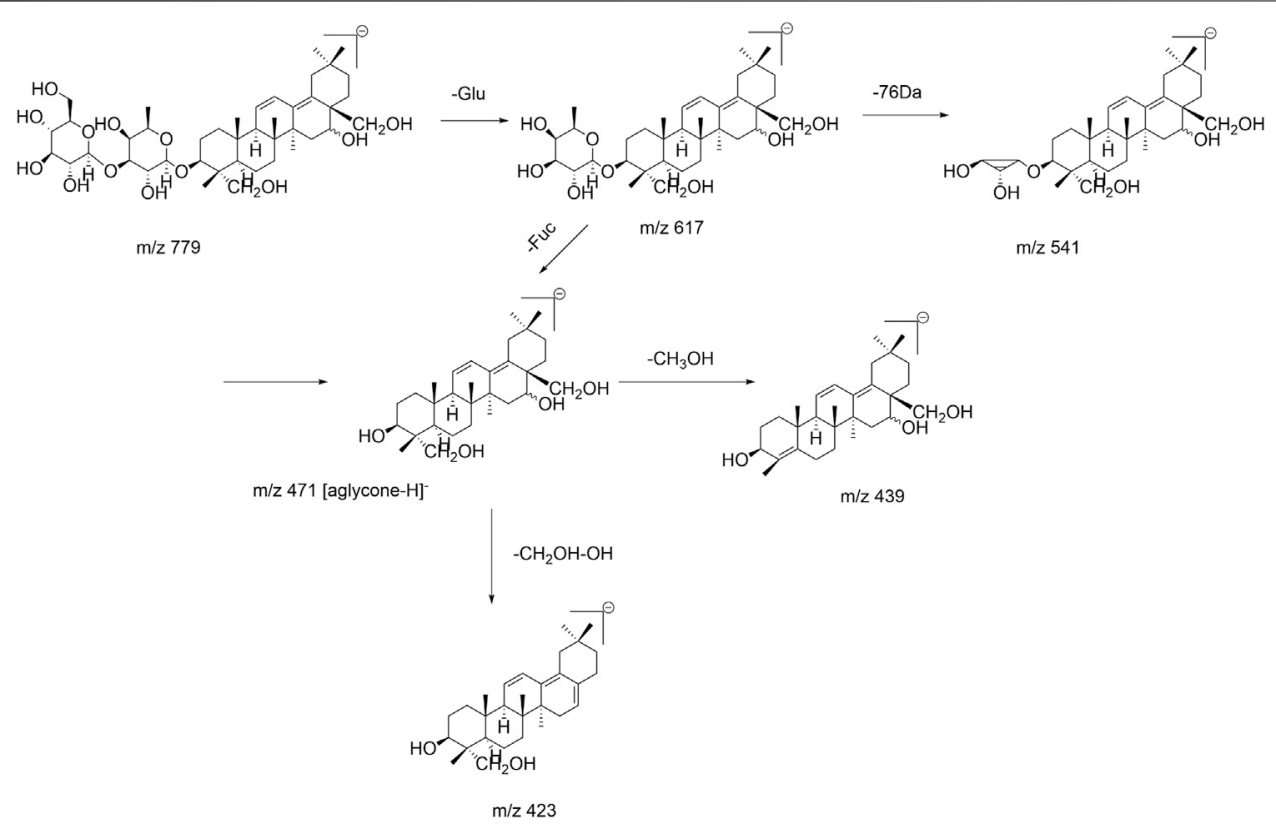

FIGURE 3 | Fragmentation pathway of $\mathrm{SSb}_{1} / \mathrm{SSb}_{2}$.

Thus, there were two double bonds $\left(\Delta^{8,11}\right.$ and $\left.\Delta^{12,13}\right)$ in the aglycone due to the diene bond conjugation, the $\mathrm{CH}_{2} \mathrm{OH}$ group at position $\mathrm{C}_{17}$ and the $\mathrm{OH}$ group at position $\mathrm{C}_{16}$, which could be lost simultaneously (loss of $48 \mathrm{Da}$ ), which produced the $\mathrm{m} / \mathrm{z} 423$ ( $\left[\text { aglycone- } \mathrm{CH}_{3} \mathrm{OH}-\mathrm{CH}_{2} \mathrm{OH}-\mathrm{OH}-\mathrm{H}\right]^{-}$) fragment ion. The loss of $\mathrm{C}_{4}-\mathrm{CH}_{3} \mathrm{OH}$ produced the fragment ion $\mathrm{m} / \mathrm{z} 391$ ([aglycone-2 $\left.\mathrm{CH}_{3} \mathrm{OH}-\mathrm{CH}_{2} \mathrm{OH}-\mathrm{OH}-\mathrm{H}\right]^{-}$). Based on the $\mathrm{m} / \mathrm{z}$ 439 ([aglycone $\left.-2 \mathrm{CH}_{3} \mathrm{OH}-\mathrm{H}\right]^{-}$), another fragmentation pathway of the aglycone produced the loss of $\mathrm{C}_{11}-\mathrm{CH}_{3} \mathrm{OH}$ and $\mathrm{C}_{4}-\mathrm{CH}_{3} \mathrm{OH}$ in turn; the fragmentation pathway of $\mathrm{SSb}_{3} / \mathrm{SSb}_{4}$ is shown in Figure 4. Similarly, for SSf, Ne-SSk, and 11a-methoxySSf, the fragmentation pathways were similar and are shown in Supplementary Figures S5-S7. Thus, the fragment ions produced by loss of a $48-\mathrm{Da}$ fragment $\left(\left[\text { aglycone }-\mathrm{CH}_{2} \mathrm{OH}-\mathrm{OH}-\mathrm{H}\right]^{-}\right)$were also a diagnostic fragment ion of type III saikosaponins in the $\mathrm{ESI}^{-}$mode.

The fragmentation behavior of Tibesaikosaponin $\mathrm{V}$ with the carbonyl $(\mathrm{C}=\mathrm{O})$ group was similar to that of $\mathrm{SSb}_{3} / \mathrm{SSb}_{4}$, but the characteristic fragment ions were produced by the loss of $30 \mathrm{Da}$ (neutral loss of $\mathrm{CH}_{2} \mathrm{O}$ ), such as $\mathrm{m} / \mathrm{z} 473$ ([aglycone-30- $]^{-}$). This behavior was the same for 23-hydroxy-13 $\beta, 28 \beta$ epoxyolean-11-ene-16-one 3-O- $\beta$-D-glucopyranosyl-( $1 \rightarrow 3)$ $\beta$-D-fucopyranoside (type I), and all had a carbonyl $(\mathrm{C}=\mathrm{O})$ group in the aglycone moiety. The fragmentation pathway is shown in Figure 5. Thus, the characteristic fragment ions produced by loss of $30 \mathrm{Da}$ could be considered the diagnostic fragment ions of saikosaponins containing carbonyl groups in the $\mathrm{ESI}^{-}$mode. This study analyzed and summarized the characteristic fragment ions and fragmentation pathways of saikosaponins containing the $\mathrm{C}=\mathrm{O}$ group for the first time, which is of great significance and benefit for the identification of these types of saikosaponins.
Retention times of type III saikosaponins revealed (Supplementary Table S1) that in the pair of epimers, the retention time of $\beta-\mathrm{OH}$ at position $\mathrm{C}_{16}$ was earlier than that of the $\alpha-\mathrm{OH}$ epimer. For type III saikosaponins, similar to type I saikosaponins, the aglycones also had a single double bond (no conjugation), and the respective maximum UV wavelengths were also approximately $190-220 \mathrm{~nm}$. The representative UV spectra are shown in Figure 8C.

\section{Analysis of Type IV Saikosaponins}

$\mathrm{SSg}$ was compared with the type II saikosaponin $\mathrm{SSb}_{1}$ (isomer of SSg) generated fragment ions that were essentially the same in $\mathrm{ESI}^{-}$, which could produce $\mathrm{m} / \mathrm{z} \quad 423$ $\left(\left[\text { aglycone- } \mathrm{CH}_{2} \mathrm{OH}-\mathrm{OH}-\mathrm{H}\right]^{-}\right)$and other fragment ions of $\mathrm{SSb}_{1}$. However, this is the first study to observe the $\mathrm{m} / \mathrm{z} 453$ ([aglycone-18-H $]^{-}$) fragment ion from $\mathrm{SSg}$, while the isomer $\mathrm{SSb}_{1}$ (type II) or SSa (type I) did not produce the same fragment. It was speculated that due to the homocyclic diene conjugation effect, the $\mathrm{OH}$ group can be lost alone; the fragmentation pathway was shown in Figure 6. Thus, in addition to the [aglycone- $\left.\mathrm{CH}_{2} \mathrm{OH}-\mathrm{OH}-\mathrm{H}\right]^{-}$, the characteristic fragment ions such as [aglycone- $\left.\mathrm{H}_{2} \mathrm{O}-\mathrm{H}\right]^{-}$produced by loss of $18 \mathrm{Da}$ could be considered a diagnostic fragment ion of type IV saikosaponins in the $\mathrm{ESI}^{-}$mode.

For type IV saikosaponins, the aglycone moieties present two double bonds (homocyclic diene conjugation), so their maximum UV wavelengths were generally around $282 \mathrm{~nm}$, and the representative UV spectra are shown in Figure 8D.

The maximum UV wavelengths, characteristic fragment ions, and fragmentation pathways of type IV saikosaponins were analyzed and summarized for the first time, and we compared differences in fragmentation patterns with other types of 


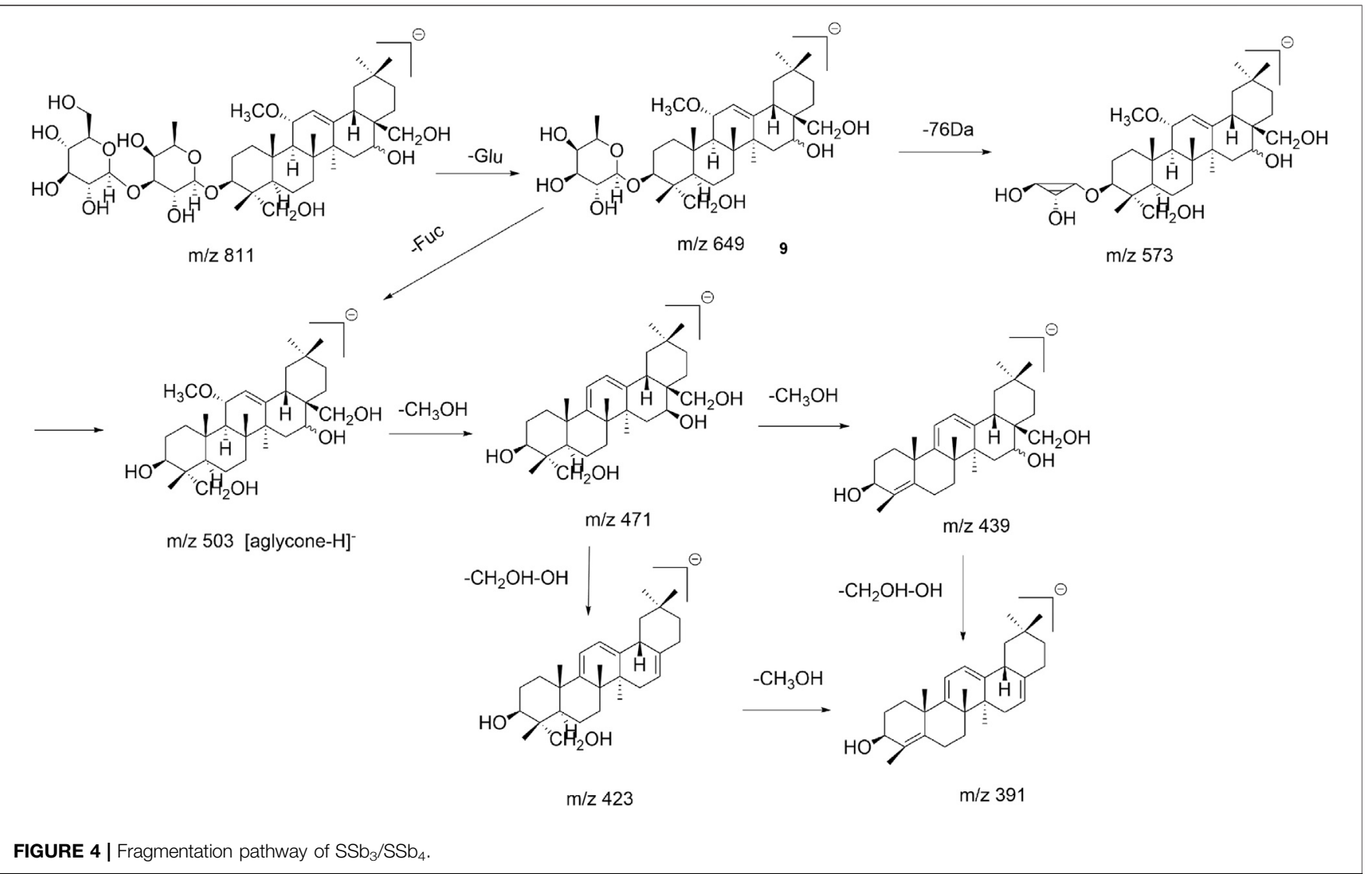

saikosaponins, which is of great significance and contributes to the identification of type IV saikosaponins.

\section{Analysis of Acetylated (Malonylated) Saikosaponins}

In the $\mathrm{ESI}^{-}$mode, acetylated saikosaponins such as $6^{\prime \prime}$-O-acetyl$\mathrm{SSb}_{3}, 2^{\prime \prime}-O$-acetyl-SSa, 6"-O-acetyl-SSa, and $6^{\prime \prime}-O$-acetyl-SSd generally produced $[\mathrm{M}-42-\mathrm{H}]^{-}$and $[\mathrm{M}-60-\mathrm{H}]^{-}$fragment ions (Supplementary Table S1), corresponding to the loss of one acetyl $\left(\mathrm{CH}_{2} \mathrm{CO}\right)$ group and the loss of one $\mathrm{CH}_{3} \mathrm{COOH}$ group, respectively. Subsequently, a series of fragment ions of the prototype saikosaponins mentioned above were produced. As an example, 6"-O-acetyl-SSa fragmentation is shown in Supplementary Figure S8. Prior studies have reported (Huang et al., 2008) that the malonylated saikosaponins produced characteristic $[\mathrm{M}-\mathrm{H}-44]^{-}$and $[\mathrm{M}-\mathrm{H}-86]^{-}$fragment ions in the $\mathrm{ESI}^{-}$mode. As an example, the fragmentation pathway of $6^{\prime \prime}-O$-malonyl-SSa is shown in Supplementary Figure S9.

For acetylated/malonylated saikosaponins in the $\mathrm{ESI}^{-}$ mode, the fragment ions of the aglycone-substituted and saccharide-substituted saikosaponins were the same, which made them difficult to distinguish; but in the $\mathrm{ESI}^{+}$mode, their fragment ions differed so that they could easily be distinguished. In the $\mathrm{ESI}^{+}$mode, 6"-O-acetyl-SSb, 2 , ${ }^{\prime \prime}-\mathrm{O}$ acetyl-SSa, 6"-O-acetyl-SSa, and $6^{\prime \prime}-O$-acetyl-SSd, whose acetyl groups are substituted by the saccharide chain, were analyzed. The fragment ions produced are shown in
Supplementary Table S2. The $\mathrm{OH}$ group in the aglycone was easily lost as were all produced [aglycone- $\left.\mathrm{nH}_{2} \mathrm{O}+\mathrm{H}\right]^{+}$ ( $\mathrm{n}=1,2$, or 3 ) fragment ions. For the $2^{\prime \prime}-O$ - acetyl-SSa, $6{ }^{\prime \prime}-O$ acetyl-SSa, and $6^{\prime \prime}-\mathrm{O}$-acetyl-SSd, the $\mathrm{OH}$ group at position $\mathrm{C}_{16}$ was lost first, which produced the $\mathrm{m} / \mathrm{z} 805\left(\left[\mathrm{M}-\mathrm{H}_{2} \mathrm{O}+\mathrm{H}\right]^{+}\right)$ fragment ion, and then $\mathrm{OH}$ groups were lost at other positions and produced the fragment ions $\mathrm{m} / \mathrm{z} 455$ ([aglycone- $\mathrm{H}_{2} \mathrm{O}+$ $\left.\mathrm{H}^{+}\right), \mathrm{m} / \mathrm{z} 437\left(\left[\text { aglycone }-2 \mathrm{H}_{2} \mathrm{O}+\mathrm{H}\right]^{+}\right.$), and $\mathrm{m} / \mathrm{z} 419$ ([aglycone $\left.-3 \mathrm{H}_{2} \mathrm{O}+\mathrm{H}\right]^{+}$. As a representative example, the fragmentation pathway of $6^{\prime \prime}$-O-acetyl-SSa is shown in Figure 7, while that of $6 "-O$-acetyl- $\mathrm{SSb}_{3}$ in the $\mathrm{ESI}^{+}$mode is shown in Supplementary Figure S10. These rules and findings were also applicable to malonylated saikosaponins (the malonyl group is substituted by the saccharide chain) according to the related literature (Liu et al., 2019) and also produce [aglycone- $\left.\mathrm{nH}_{2} \mathrm{O}+\mathrm{H}\right]^{+}(\mathrm{n}=1$ or 2 or 3$)$ in the $\mathrm{ESI}^{+}$ mode, while the fragment ions $\mathrm{m} / \mathrm{z} 497$ ([aglycone $+42-\mathrm{H}_{2} \mathrm{O}+$ $\left.\mathrm{H}]^{+}\right)$and $\mathrm{m} / \mathrm{z} 479\left(\left[\text { aglycone }+42-2 \mathrm{H}_{2} \mathrm{O}+\mathrm{H}\right]^{+}\right.$indicate that the acetyl group is substituted by the aglycone. For example, the fragmentation pathway in the $\mathrm{ESI}^{+}$mode of 23-O-acetyl-SSa (the malonyl group is substituted by the aglycone) (Liu et al., 2019) is shown in Supplementary Figure S11.

Retention times were analyzed according to standard substances and according to that reported in the literature (Zhao et al., 1996; Huang et al., 2008). The retention time of acetylated saikosaponins is later than that of the prototype saikosaponins. The acetyl substituent at different positions of 


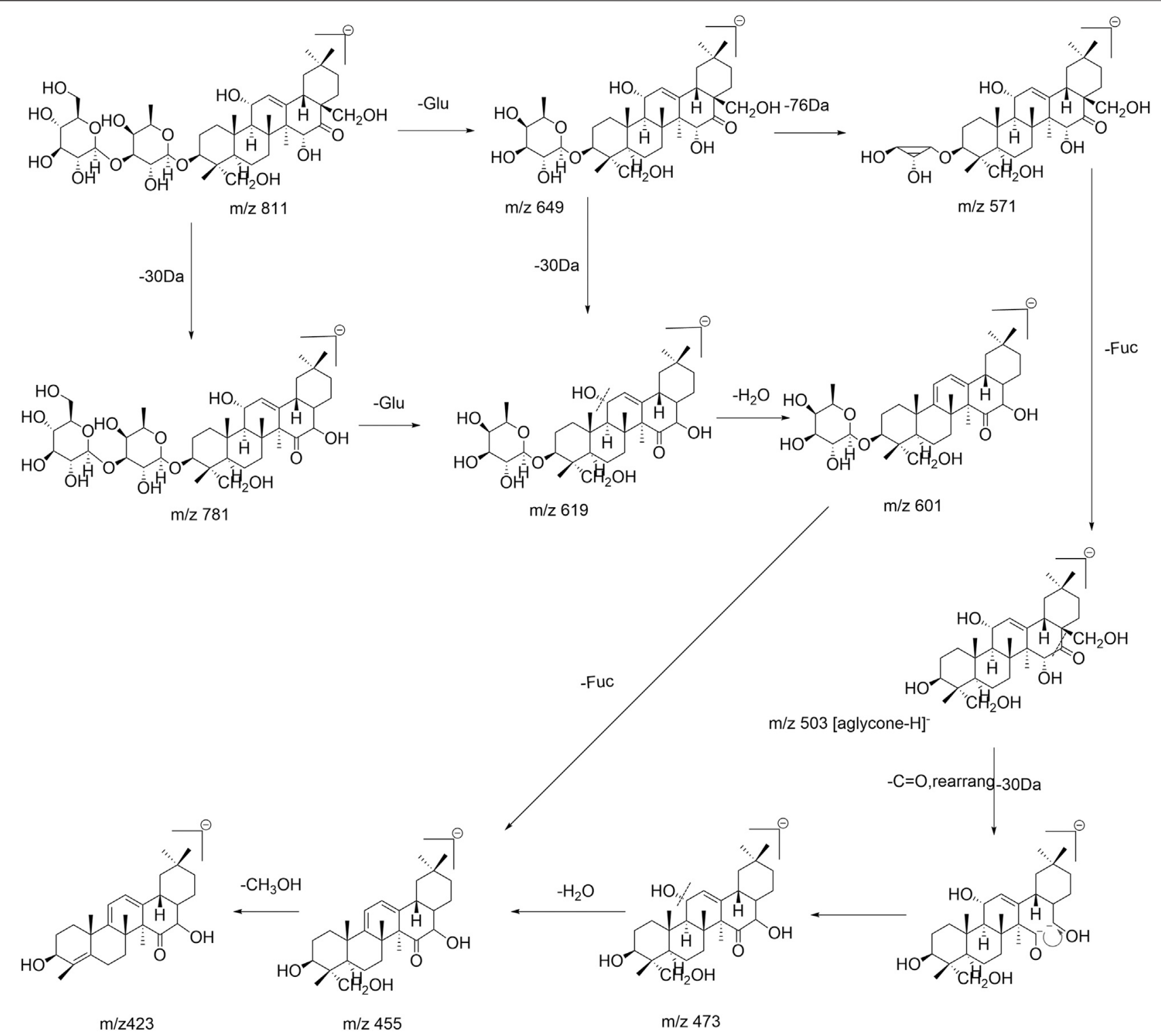

FIGURE 5 | Fragmentation pathway of Tibesaikosaponin V.

the saccharide chain can affect the retention time; the retention time of the acetyl substituent at the beginning of the saccharide chain is earlier than that of the acetyl substituent at the rear position. For acetylated-SSa, the acetyl group can be substituted at different positions on the terminal glucose of the saccharide chain, so that the retention times for $2^{\prime \prime}-O$-acetyl-SSa, $3^{\prime \prime}-O$-acetyl-SSa, $4^{\prime \prime}-O$-acetyl-SSa, and $6^{\prime \prime}-O$-acetyl-SSa range from earlier to later.

Thus, the fragment ions $[\mathrm{M}-42-\mathrm{H}]^{-}$and $[\mathrm{M}-60-\mathrm{H}]^{-}$(or $[\mathrm{M}-\mathrm{H}-44]^{-}$and $\left.[\mathrm{M}-\mathrm{H}-86]^{-}\right)$are diagnostic fragment ions for acetylated (or malonylated) saikosaponins in the $\mathrm{ESI}^{-}$mode, combined with the analysis of their respective $\mathrm{m} / \mathrm{z}$ values for [aglycone- $\left.\mathrm{nH}_{2} \mathrm{O}+\mathrm{H}\right]^{+}$in the $\mathrm{ESI}^{+}$mode, and the order of retention times can be combined to speculate the specific position of their acetyl/malonyl group.

\section{Summary: Strategy for Identification of Saikosaponins} Among the isomers, several pairs of epimeric saikosaponins such as $\mathrm{SSa} / \mathrm{SSd}, \mathrm{SSb}_{3} / \mathrm{SSb}_{4}, \mathrm{SSb}_{1} / \mathrm{SSb}_{2}$, Prosaikogenin a/Prosaikogenin $\mathrm{d}$, and Prosaikogenin g/Prosaikogenin $\mathrm{f}$ differed only in the configuration of the $\mathrm{OH}$ group at position $\mathrm{C}_{16}$. Of these, saikosaponins with only one double bond in the aglycone moiety (types I and III), and the retention time of $\beta-\mathrm{OH}$ at the $\mathrm{C}_{16}$ position was earlier than that of the $\alpha-\mathrm{OH}$ epimer, such as $\mathrm{SSa} / \mathrm{SSd}, \mathrm{SSb}_{3} / \mathrm{SSb}_{4}$, and Prosaikogenin g/Prosaikogenin $\mathrm{f}$. In contrast, for type II saikosaponins (whose aglycone is an isocyclic diene), the retention time of $\beta-\mathrm{OH}$ at position $\mathrm{C}_{16}$ was later than that of the $\alpha-\mathrm{OH}$ epimer, such as $\mathrm{SSb}_{1} / \mathrm{SSb}_{2}$ and Prosaikogenin a/Prosaikogenin d. For acetylated (or malonylated) saikosaponins, the combination of retention times is helpful to infer 

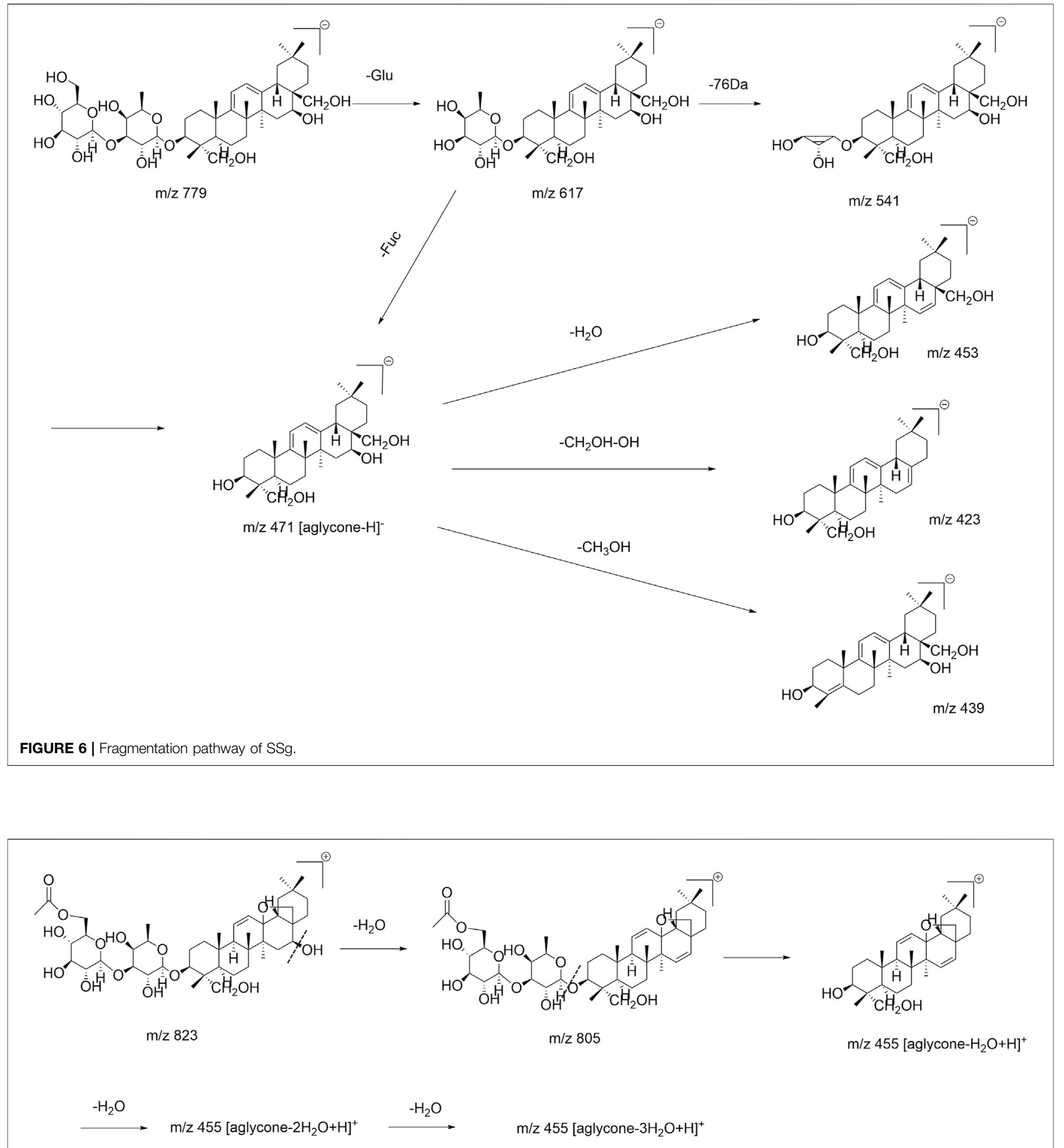

FIGURE 7 | Fragmentation pathway of $6^{\prime \prime}$-O-acetyl-SSa in the positive ion mode $\left(\mathrm{ESI}^{+}\right)$.

the specific position of acetyl (or malonyl) substituents of the saccharide chain.

The maximum UV absorption wavelengths of saikosaponins can be summarized as follows: saikosaponins (such asSSa/SSd/
$\mathrm{SSc} / \mathrm{SSb}_{3} / \mathrm{SSb}_{4} / \mathrm{SSe} / \mathrm{SSf}$ ) with the aglycone as the monoene (types I and III) generally located around the terminal ends, ranged 190-220 nm; saikosaponins (such as $\mathrm{SSb}_{1} / \mathrm{SSb}_{2} / \mathrm{SSc} / \mathrm{SSh}$ ) with the aglycone as the isocyclic diene (type II), approximately 


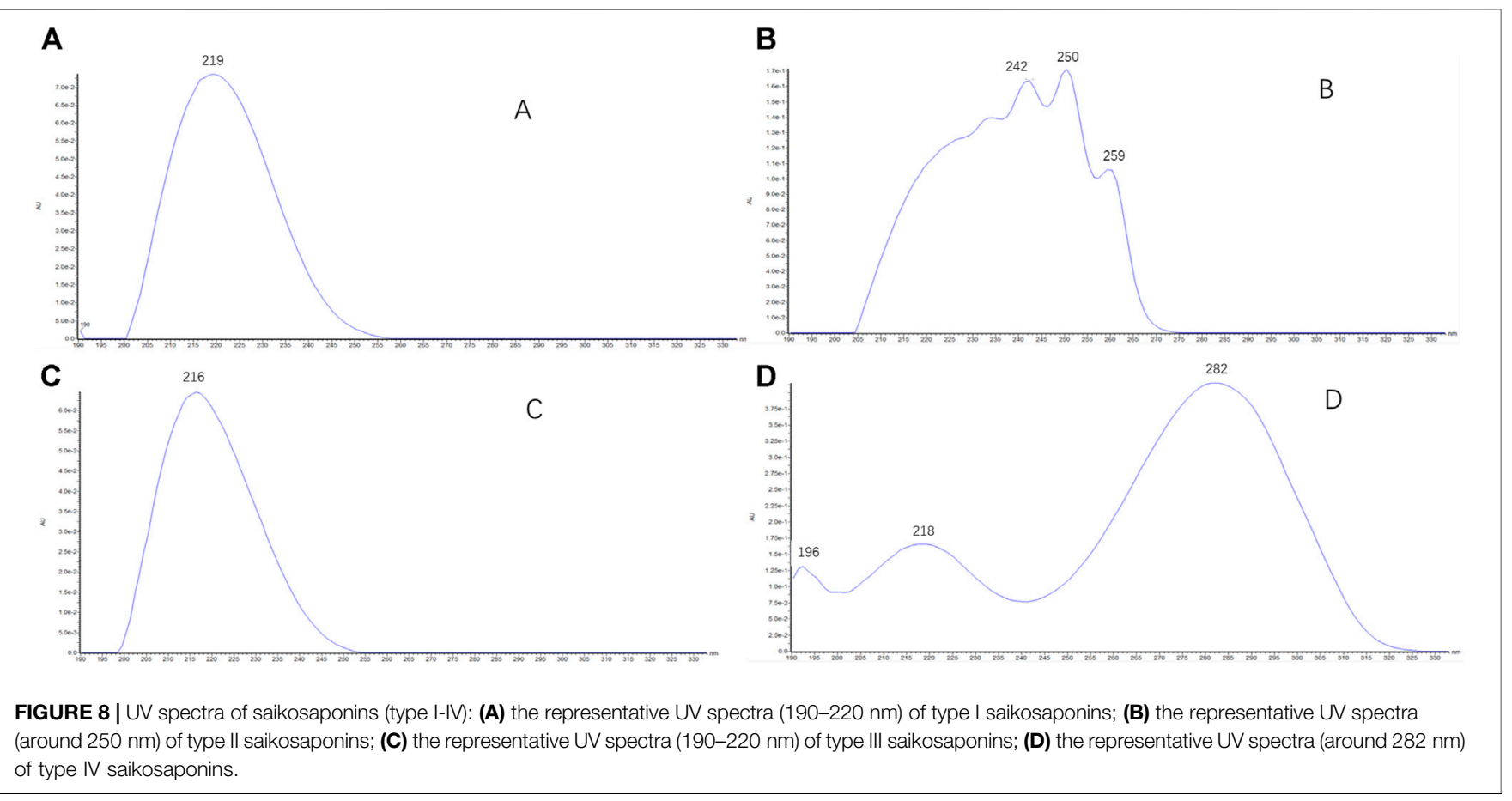

$250 \mathrm{~nm}$; saikosaponins (such as SSg/SSi) with the aglycone as the homocyclic diene (type IV), approximately $282 \mathrm{~nm}$. The representative UV spectra are shown in Figure 8.

The characteristic mass losses and typical fragmentation pathways for different types of saikosaponins can be summarized as follows: all compounds produced a base peak at $[\mathrm{M}-\mathrm{H}]^{-}$, and the molecular formula of each compound could be determined based on its exact mass. In addition to maximum UV absorption wavelengths, the type of aglycones could be inferred through their characteristic neutral losses of the aglycone moiety, such as type II and III (characteristic loss of $48 \mathrm{Da}$ ) and type IV (characteristic loss of 48 and $18 \mathrm{Da}$ ). The number and sequences of saccharide chains could be inferred through the characteristic neutral losses of sugar moieties, such as rhamnose (Rha, $146 \mathrm{Da}$ ), furanose (Fuc, 146 and $76 \mathrm{Da}$ ), xylose (Xyl, $132 \mathrm{Da})$, and glucose (Glu, $162 \mathrm{Da})$. Other typical losses were those such as $\mathrm{OCH}_{4}(32 \mathrm{Da}), \mathrm{H}_{2} \mathrm{O}(18 \mathrm{Da}), \mathrm{CH}_{3} \mathrm{OH}(32 \mathrm{Da})$, $\mathrm{CH}_{2} \mathrm{O}(30 \mathrm{Da}), \mathrm{AcOH} / \mathrm{C}_{2} \mathrm{H}_{2} \mathrm{O}(60 \mathrm{Da} / 42 \mathrm{Da})$, and $\mathrm{C}_{3} \mathrm{H}_{2} \mathrm{O}_{3} / \mathrm{CO}_{2}$ $(80 \mathrm{Da} / 44 \mathrm{Da})$, which corresponded to the presence of an $\mathrm{OCH}_{3}$ group, an $\mathrm{OH}$ group, a $\mathrm{CH}_{2} \mathrm{OH}$ group, a $\mathrm{C}=\mathrm{O}$ group, an acetyl group, and a malonyl group, respectively. Figure 9 illustrates the strategy for identification of saikosaponins.

\section{UPLC-PDA-Q/TOF-MS Analysis of Saikosaponin Extracts From BMS}

In the $\mathrm{ESI}^{-}$mode, the base peak ion (BPI) chromatogram of the total saikosaponin extract from BMS is shown in Figure 10. Types I, II, III, and IV and some other types of saikosaponins were identified and initially characterized from the total saikosaponin extract of BMS, and when combined with the respective retention times and fragment ions in the $\mathrm{ESI}^{+}$mode, the specific position of the acetyl/ malonyl substituent of acetylated/malonylated saikosaponins could be deduced. A total of 109 saikosaponin compounds were structurally identified and characterized, and the information on their identification, chromatographic retention time (RT), molecular formula, fragment ions, and maximum UV wavelengths is provided in Supplementary Datasheet S1. A total of 22 saikosaponin compounds were confirmed by saikosaponin standards (marked with "*" in Supplementary Datasheet S1), 25 saikosaponins were new compounds (marked with "\#\#" in Supplementary Datasheet S1), and 60 saikosaponins were first discovered in BMS (marked with "\#\#" in Supplementary Datasheet S1).

\section{Characterization of Compounds $40,42,58$, and 71 (Type I)}

According to the fragment ions, retention times, and maximum UV wavelength of compounds 40,42, 58, and 71 (Supplementary Datasheet S1), their characteristic mass losses and UV maximum absorption wavelengths $(190-220 \mathrm{~nm})$ are consistent with those of type I saikosaponins, so it was inferred that these compounds had the same aglycones or similar aglycones (with the morehydroxyl substituents at different positions) as type I saikosaponins. 11 type I saikosaponins were identified in this study, including saikosaponin compounds compared with type I related standard substances (acetylated/malonylated type I saikosaponins were described separately below and not included).

In the $\mathrm{ESI}^{-}$mode, the fragment ions of compound 42 had fragment ions $\mathrm{m} / \mathrm{z} 633\left(\left[\mathrm{M}-\mathrm{C}_{6} \mathrm{H}_{10} \mathrm{O}_{5}-\mathrm{H}\right]^{-}\right), \mathrm{m} / \mathrm{z} \quad 557$ $\left(\left[633-\mathrm{C}_{3} \mathrm{H}_{8} \mathrm{O}_{2}-\mathrm{H}\right]^{-}\right.$, the specific fragmentation pathway of Fuc), and $\mathrm{m} / \mathrm{z} 487\left(\left[633-\mathrm{C}_{6} \mathrm{H}_{10} \mathrm{O}_{4}-\mathrm{H}\right]^{-}\right.$, aglycone ion), revealing the number and sequence of its saccharide chain, and based on the fragment ions $\mathrm{m} / \mathrm{z} \quad 455$ ([aglycone- $\left.\mathrm{CH}_{3} \mathrm{OH}-\mathrm{H}\right]^{-}$) and $\mathrm{m} / \mathrm{z} 437\left(\left[455-\mathrm{H}_{2} \mathrm{O}-\mathrm{H}\right]^{-}\right)$, 


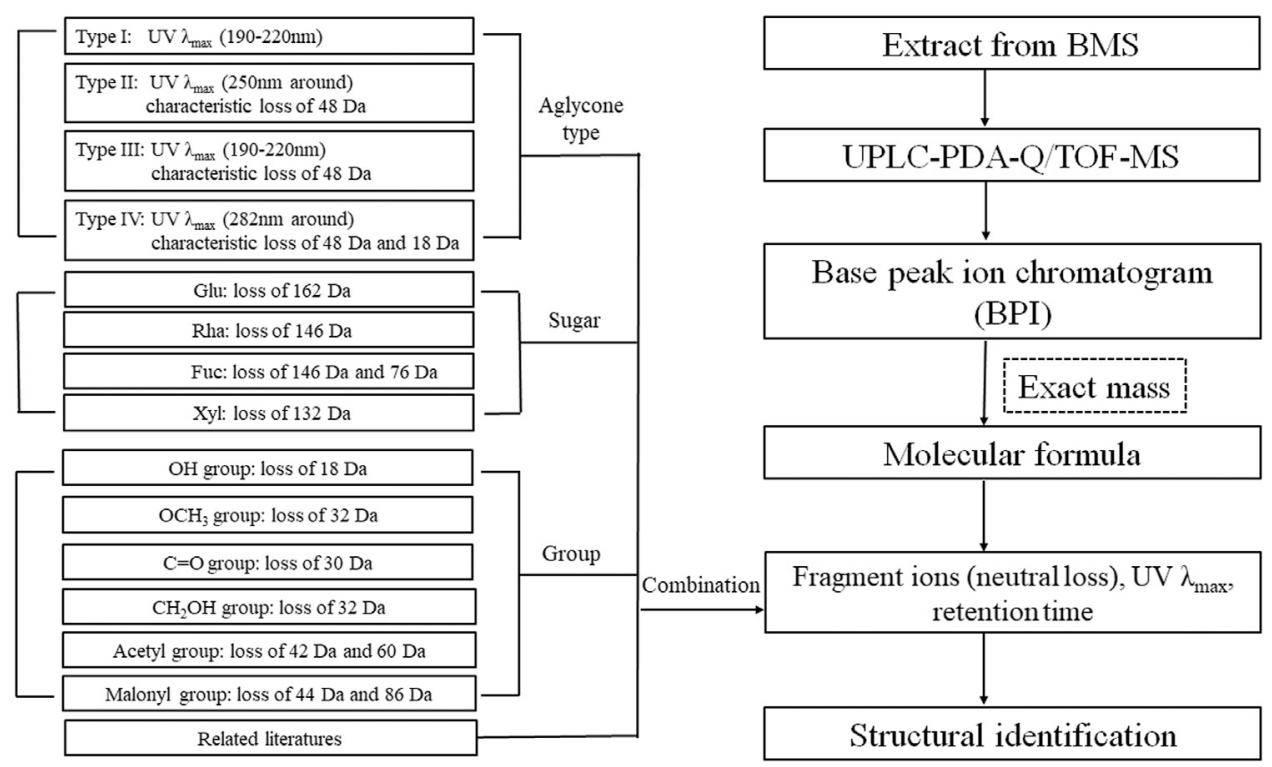

FIGURE 9 | Flowchart for the systematic identification of saikosaponins by UPLC-PDA-Q/TOF-MS combined with a screening method.

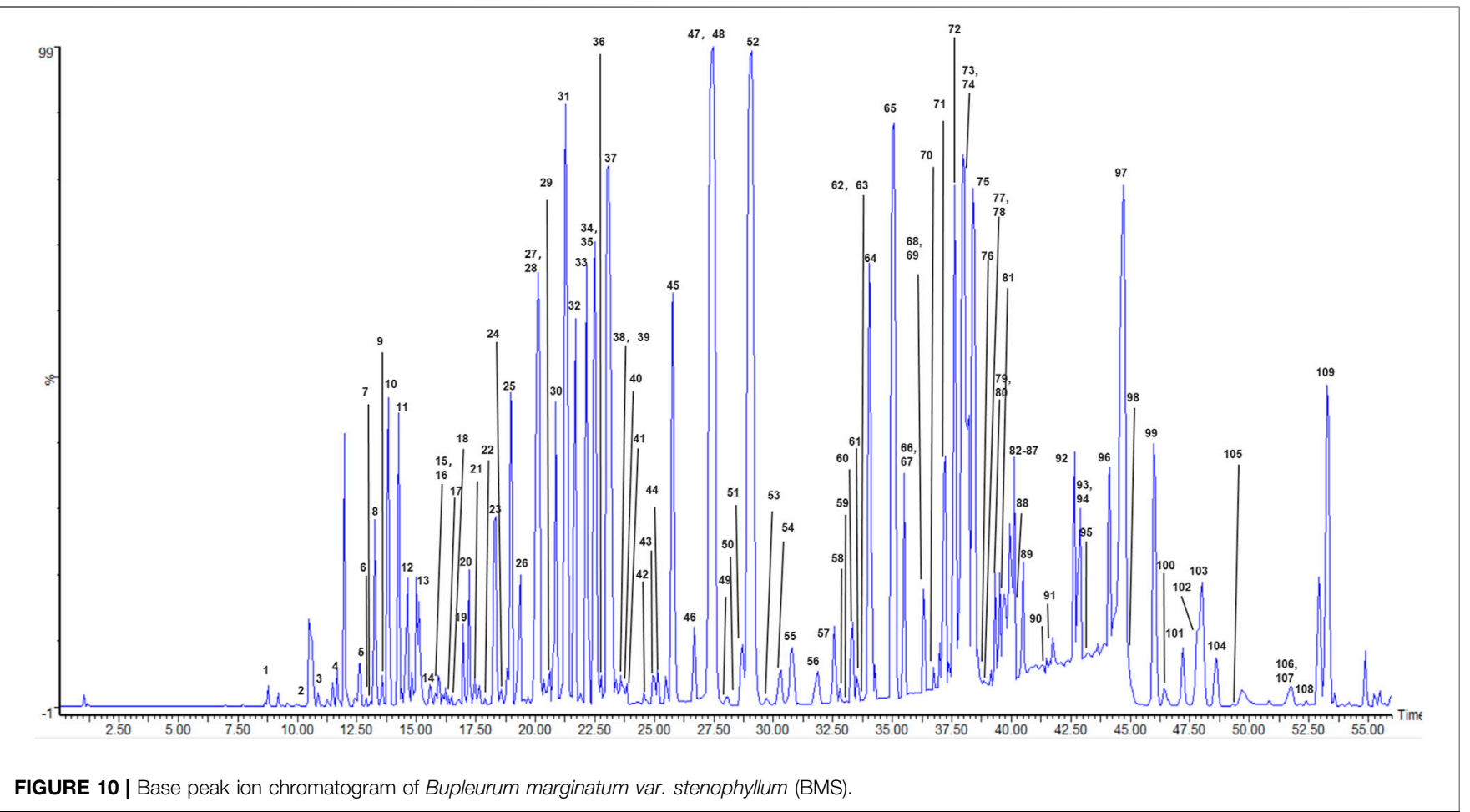

which indicated that it comprised one more hydroxyl substituent at the aglycone moiety compared with SSa, compound 42 was identified as clinoposaponin XIV based on a literature review (Miyase and Matsushima, 1997); the fragmentation pathway is shown in Supplementary Figure S12. The same analytical procedure was employed to identify compounds 40, 58, and 71. Compounds 40 and 58 were identified as Sandrosaponin
VII (Sánchez-Contreras et al., 2000) and Clinoposaponin XII (Cui et al., 2014). Compound 71 was initially identified as Bupleruoside I or Buddlejasaponin IV (Barrero et al., 2000; Zhu et al., 2018); the two differed only in the order of the saccharide chain and could not be distinguished temporarily. The structures of compounds 40,58, and 71 are shown in Supplementary Figure S13. 
Characterization of Compounds 13, 38, 31, 33, 2, 14, 7, $50,76,17,77$, and 79 (Type II)

According to the fragment ions, retention times, and maximum UV wavelength (254 $\mathrm{nm}$ around), for compounds $13,38,31,33$, 2, 14, 7, 50, 76, 17, 77, and 79 (Supplementary Datasheet S1), their characteristic mass losses (characteristic loss of $48 \mathrm{Da}$ ) and UV maximum absorption wavelengths (approximately $250 \mathrm{~nm}$ ) are consistent with those of type II saikosaponins, so they have the same aglycones or similar aglycone structures (probably with the more $\mathrm{OH}$ or $\mathrm{C}=\mathrm{O}$ substituents at different positions) as type II saikosaponins. 15 type II saikosaponins were identified in this study, including saikosaponin compounds compared with related type II standard substances (acetylated/malonylated type II saikosaponins were described separately below and not included).

In the $\mathrm{ESI}^{-}$mode, compounds 31 and 33 shared the same molecular formula. Their fragment ions all showed $\mathrm{m} / \mathrm{z} 779$ $\left(\left[\mathrm{M}-\mathrm{C}_{6} \mathrm{H}_{10} \mathrm{O}_{5}-\mathrm{H}\right]^{-}\right), \mathrm{m} / \mathrm{z} 795\left(\left[\mathrm{M}-\mathrm{C}_{6} \mathrm{H}_{10} \mathrm{O}_{4}-\mathrm{H}\right]^{-}\right), \mathrm{m} / \mathrm{z} 633$ $\left(\left[\mathrm{M}-\mathrm{C}_{6} \mathrm{H}_{10} \mathrm{O}_{5}-\mathrm{C}_{6} \mathrm{H}_{10} \mathrm{O}_{4}-\mathrm{H}\right]^{-}\right), \quad$ and $\mathrm{m} / \mathrm{z} \quad 471$ ([M-2 $\left.\mathrm{C}_{6} \mathrm{H}_{10} \mathrm{O}_{5}-\mathrm{C}_{6} \mathrm{H}_{10} \mathrm{O}_{4}-\mathrm{H}\right]^{-}$, aglycone ion), which revealed the number and sequences of its saccharide chain. Furthermore, based on the diagnostic fragment ions $\mathrm{m} / \mathrm{z} 439$ ([aglycone- $\left.\mathrm{CH}_{3} \mathrm{OH}-\mathrm{H}\right]^{-}$) and $\mathrm{m} / \mathrm{z} \quad 423$ ([aglycone- $\left.\mathrm{CH}_{2} \mathrm{OH}-\mathrm{OH}-\mathrm{H}\right]^{-}$, produced by the loss of $48 \mathrm{Da}$ (characteristic loss of type II saikosaponins), it was concluded that these compounds had the same aglycone moieties as $\mathrm{SSb}_{1} /$ $\mathrm{SSb}_{2}$. Based on the combined order of their retention times and the abundance of the $\mathrm{m} / \mathrm{z} 423$ fragment ion of compound 31, which was smaller than the $\mathrm{m} / \mathrm{z} 439$ fragment ion, and compound 33 showing opposite fragments, it was inferred that compound 31 was SSs ( $\alpha-\mathrm{OH}$ at position $\mathrm{C}_{16}$ ) and compound 33 was $\mathrm{SSn}(\beta-\mathrm{OH}$ at position $\mathrm{C}_{16}$ ) (Fang et al., 2017). The fragmentation pathway is shown in Supplementary Figure S14. The same analytical procedure was employed to identify compounds 13 and 38 (having the same molecular formula), and compounds 13 and 38 were identified as SSI ( $\alpha-\mathrm{OH}$ at position $\mathrm{C}_{16}$ ) and Tibesaikosaponin IV $\left(\beta-\mathrm{OH}\right.$ at position $\left.\mathrm{C}_{16}\right)$, respectively ( $\mathrm{Yu}$ et al., 2013; Fang et al., 2017); their fragmentation pathways are shown in Supplementary Figure S15.

Employing the same analytical procedure to analyze the characteristic fragment ions and formulas of compounds 2,14 , 7, 50, and 76, their saccharide chains and aglycone structures could be deduced. Through a literature review, compounds 2 and 14 were identified as SSq or its isomer (Huang et al., 2008), and the fragmentation pathway of SSq is shown in Supplementary Figure S16. Compound 7 was identified as SSr (Barrero et al., 2000). The fragment ions and formula of compound 50 were the same as those of SSh, which was identified as Saponin BK1 (isomer of SSh) (Sinha et al., 2021). As for compound 76, its formula and fragment ions were the same as those of SSe (Compound 90, confirmed by the standard substance) and was identified as SSm (Shan et al., 2018). The structures of compounds 7, 50, and 76 are shown in Supplementary Figure S17.

Compounds 17 and 77 shared the same molecular formula and fragment ions, and the diagnostic fragment ions produced from the loss of a 30-Da fragment (the neutral loss of $\mathrm{CH}_{2} \mathrm{O}$ ) included $\mathrm{m} / \mathrm{z} \quad 763 \quad\left([\mathrm{M}-30-\mathrm{H}]^{-}\right), \quad \mathrm{m} / \mathrm{z} \quad 601$ $\left(\left[\mathrm{M}-\mathrm{C}_{6} \mathrm{H}_{10} \mathrm{O}_{5}-30-\mathrm{H}\right]^{-}\right)$, and $\mathrm{m} / \mathrm{z} 455$ ([aglycone-30- $\left.]^{-}\right)$; it was inferred that compounds 17 and 77 had a $\mathrm{C}=\mathrm{O}$ group on the aglycone moiety. Based on other fragment ions, their saccharide chains and aglycone structures could be deduced, and through a review of the related literature, they were identified as Tibesaikosaponin II or its isomer (Fang et al., 2017); the fragmentation pathway is shown in Supplementary Figure S18. For compound 79, its formula and fragment ions were the same as those of compound 99 (23-hydroxy-13 $\beta, 28 \beta$ epoxyolean-11-ene-16-one 3-O- $\beta$-D-glucopyranosyl-(1-3)- $\beta$-Dfucopyranoside, confirmed by the standard substance), combined with the maximum UV wavelength $(250 \mathrm{~nm})$ and a review of the related literature ( $\mathrm{Li}$ et al., 2015); it was identified as $3 \beta, 23,28$-trihydroxyolean-11,13 (18)-diene-16-one 3-O- $\beta$-Dglucopyranosyl-(1-3)- $\beta$-D-fucopyranoside, and its structure is shown in Supplementary Figure S19.

\section{Characterization of Compounds 8, 30, 3, 51, 54, 25, and 27 (Type III)}

According to the fragment ions, retention times, and maximum UV wavelength of compounds $8,30,3,51,54,25$, and 27 (Supplementary Datasheet S1), their characteristic mass losses (characteristic loss of $48 \mathrm{Da}$ ) and UV maximum absorption wavelengths (190-220 nm) are consistent with those of type III saikosaponins, and it was inferred that these compounds have the same aglycones or similar aglycones as type III saikosaponins. 13 type III saikosaponins were identified in this study, including saikosaponin compounds compared with related type III standard substances (acetylated/malonylated type III saikosaponins were described separately below and not included).

Compounds 8 and 30 shared the same molecular formula as $\mathrm{C}_{42} \mathrm{H}_{68} \mathrm{O}_{14}$, and the fragment ions of compound 8 produced $\mathrm{m} / \mathrm{z}$ $633\left(\left[\mathrm{M}-\mathrm{C}_{6} \mathrm{H}_{10} \mathrm{O}_{5}-\mathrm{H}\right]^{-}\right), \mathrm{m} / \mathrm{z} 557\left(\left[633-\mathrm{C}_{3} \mathrm{H}_{8} \mathrm{O}_{2}-\mathrm{H}\right]^{-}\right.$, the specific fragmentation pathway of Fuc), and $\mathrm{m} / \mathrm{z} \quad 487$ $\left(\left[633-\mathrm{C}_{6} \mathrm{H}_{10} \mathrm{O}_{4}-\mathrm{H}\right]^{-}\right.$, aglycone ion), which revealed the number and sequences of its saccharide chain, and based on the diagnostic fragment ions $\mathrm{m} / \mathrm{z} 455$ ([aglycone- $\left.\mathrm{CH}_{3} \mathrm{OH}-\mathrm{H}\right]^{-}$) and $\mathrm{m} / \mathrm{z} 407\left(\left[455-\mathrm{CH}_{2} \mathrm{OH}-\mathrm{OH}-\mathrm{H}\right]^{-}\right)$, its aglycone moiety could be deduced. Thus, compound 8 was identified as SSt (or Bupleuroside IX) by reviewing the related literature (Yu et al., 2014). The fragmentation pathway of SSt is shown in Supplementary Figure S20. For compound 30, in addition to the above fragment ions of compound 8 , additional fragment ions produced from the loss of $30 \mathrm{Da}$ (neutral loss of $\mathrm{CH}_{2} \mathrm{O}$ ) appeared, which included fragment ions $\mathrm{m} / \mathrm{z} 765\left([\mathrm{M}-30-\mathrm{H}]^{-}\right), \mathrm{m} / \mathrm{z} 603$ $\left(\left[\mathrm{M}-\mathrm{C}_{6} \mathrm{H}_{10} \mathrm{O}_{5}-30-\mathrm{H}\right]^{-}\right)$, and $\mathrm{m} / \mathrm{z} 457$ ([aglycone-30- $\left.\mathrm{H}\right]^{-}$), which indicated the presence of a $\mathrm{C}=\mathrm{O}$ group on the aglycone moiety and was identified as Bupleuroside VI (Liang et al., 2014). The structure is shown in Supplementary Figure S21.

Compound 3, based on the fragment ions and formula, was identified as Rotundioside $\mathrm{P}$ by reviewing the related literature (Fujioka et al., 2006), and its fragmentation pathway is shown in Supplementary Figure S22. The same analytical procedure was employed to identify compounds 25 and 27 , which presented an additional hydroxyl substituent at the aglycone moiety compared 
with compounds SSa/SSd, and combined with the order of the respective retention times, it was speculated that compound 25 was hydroxysaikosaponin a and compound 27 was hydroxysaikosaponin d (Huang et al., 2008); both structures are shown in Supplementary Figure S23. Compounds 51 and 54 shared the same molecular formula and fragment ion pattern as SSf (compound 52, confirmed by the standard substance) and were identified as the isomer of SSf, in which we speculated that the position of the double bond was different from that of SSf.

\section{Characterization of Compounds 6, 9, and 10 (Types IV and VI)}

For compound 6, the fragment ions $\mathrm{m} / \mathrm{z} 647$ $\left(\left[\mathrm{M}-\mathrm{C}_{6} \mathrm{H}_{10} \mathrm{O}_{5}-\mathrm{H}\right]^{-}\right), \mathrm{m} / \mathrm{z} 571\left(\left[647-\mathrm{C}_{3} \mathrm{H}_{8} \mathrm{O}_{2}-\mathrm{H}\right]^{-}\right.$, the specific fragmentation pathway of Fuc), and $\mathrm{m} / \mathrm{z} 501$ $\left(\left[647-\mathrm{C}_{6} \mathrm{H}_{10} \mathrm{O}_{4}-\mathrm{H}\right]^{-}\right.$, aglycone ion) revealed the number and sequences of the saccharide chain. According to the diagnostic fragment ions $\mathrm{m} / \mathrm{z} 453$ ([aglycone- $\left.\mathrm{CH}_{2} \mathrm{OH}-\mathrm{OH}-\mathrm{H}\right]^{-}$) and $\mathrm{m} / \mathrm{z}$ 483 ([aglycone $\left.-\mathrm{H}_{2} \mathrm{O}-\mathrm{H}\right]^{-}$) and combined with the maximum UV wavelength $(282 \mathrm{~nm})$, it was inferred that compound 6 had a similar aglycone moiety to type IV saikosaponins and was speculated to be an isomer of Bupleuroside $\mathrm{V}$, with the following structure, $3 \beta, 16 \alpha, 23,28$-Tetrahydroxy-olean-9,12 (13)-dien-29-oic acid 3-O- $\beta$ - D-glucopyranosyl-(1-3)- $\beta$-Dfucopyranoside. Its fragmentation pathway is shown in Supplementary Figure S24. 3 type IV saikosaponins were identified in this study, including saikosaponin compounds compared with related type IV standard substances.

For compound 10, the number and sequence of its saccharide chain was deduced from the fragment ions (Supplementary Datasheet S1) $\mathrm{m} / \mathrm{z} 453$ ([aglycone- $\left.\mathrm{CH}_{2} \mathrm{OH}-\mathrm{OH}-\mathrm{H}\right]^{-}$) and $\mathrm{m} / \mathrm{z} 469\left(\left[\text { aglycone- } \mathrm{CH}_{3} \mathrm{OH}-\mathrm{H}\right]^{-}\right)$, but without $\mathrm{m} / \mathrm{z} 483$ ([aglycone $\left.\left.-\mathrm{H}_{2} \mathrm{O}-\mathrm{H}\right]^{-}\right)$, and combined with its maximum UV wavelength $(251 \mathrm{~nm})$ and formula, it was identified as Bupleuroside V using a literature review (Yoshikawa, 1997). Its fragmentation pathway is shown in Supplementary Figure S25. The same analytical procedure was employed to identify compound 9, which was identified as $3 \beta, 16 \alpha, 23,28$-tetrahydroxyolean-11,13 (18)-dien-30-oicacid-3-O- $\beta$-D-glucopyranosyl-(12)- $\beta$-D-glucopyranosyl-(1-3)- $\beta$-D-fucopyranoside (Liang et al., 2013); its structure is shown in Supplementary Figure S26. Compounds 9 and 10 belonged to the type VI saikosaponins.

Characterization of Compounds $1,5,11-12,15-16$, 19-23, 26, 29, 32, 35, 41, 44-45, 49, 60, 68, 72, 74, and 94-96 (Other Types)

According to the formula, fragment ions, retention times, and maximum UV wavelength of compounds 1, 5, 11-12, 15-16, $19-23,26,29,32,35,41,44-45,49,60,68,72,74$, and 94-96 (Supplementary Datasheet S1), the number and sequences of the saccharide chain can be deduced. In addition, the structures of the aglycone can be identified through further analysis of their fragment ions.

For compound 1, its molecular ion and fragment ions were $18 \mathrm{Da}$ more than those of compound 8 (SSt), and combined with its formula, this suggested it had an additional hydroxyl substituent at the aglycone moiety compared with SSt; thus, compound 1 was tentatively identified as hydroxysaikosaponin t. Its fragmentation pathway is shown in Supplementary Figure S27. The same analytical procedure was employed to identify compounds 23,11,35, 44, 60, and 49. Compound 23 had an additional hydroxyl substituent at the aglycone moiety compared with SSh (compound 56, confirmed by the standard substance); thus, compound 23 was tentatively identified as hydroxysaikosaponin h (11a-hydroxy-SSh). Similarly, compounds 11, 35, 44, and 60 had an additional hydroxyl substituent at the aglycone moiety compared with SSc (compound 47, confirmed by the standard substance); thus, they were tentatively identified as hydroxysaikosaponin c (11ahydroxy-SSc) or its isomer (Ebata et al., 1996); for compound 49, its retention time followed that of hydroxysaikosaponin a and hydroxysaikosaponin d (compounds 25 and 27). The diagnostic fragment ions $\mathrm{m} / \mathrm{z} 439$ ([aglycone- $\left.\mathrm{CH}_{3} \mathrm{OH}-\mathrm{H}\right]^{-}$) and $\mathrm{m} / \mathrm{z} 423$ ([aglycone- $\left.\mathrm{CH}_{2} \mathrm{OH}-\mathrm{OH}-\mathrm{H}\right]^{-}$) and the abundance of the fragment ion $\mathrm{m} / \mathrm{z} 423$ were smaller than the fragment $\mathrm{m} / \mathrm{z}$ 439 ; thus, it was speculated to be hydroxysaikosaponin $b_{2}$ $\left(\alpha-\mathrm{OH}\right.$ at position $\mathrm{C}_{16}$ ). The structures of hydroxysaikosaponin c, hydroxysaikosaponin $h$, and hydroxysaikosaponin $b_{2}$ are shown in Supplementary Figure S28.

For compound 32, its formula and fragment ions indicated that it had an additional $\mathrm{OC}_{2} \mathrm{H}_{5}$ substituent at the aglycone moiety compared with SSs/SSn (compound 31/33), based on the abundance of the $\mathrm{m} / \mathrm{z} 423$ ([aglycone- $\left.\mathrm{OC}_{2} \mathrm{H}_{5}-48-\mathrm{H}\right]^{-}$) fragment ion, which was smaller than $\mathrm{m} / \mathrm{z} 439$ ([aglycone- $\left.\left.\mathrm{OC}_{2} \mathrm{H}_{5}-32-\mathrm{H}\right]^{-}\right)$when, and combined with its retention time, it was identified as $11 \alpha$-ethoxyl-SSs ( $\alpha-\mathrm{OH}$ at position $\mathrm{C}_{16}$ ). Similarly, compounds 72 and 74 were identified as $11 a$-ethoxyl-SSb$b_{2}$ and $11 a$-ethoxyl-SSb$b_{1}$, respectively, while compounds 96 and 45 were identified as $11 a$-butoxyl-SSb $b_{2}$ and $11 a$-ethoxyl-SSh, respectively. Their fragmentation pathways are shown in Supplementary Figure S29-S32.

Compounds 4,12,16,19, and 20 shared the same molecular formula and fragment ions, and they could be deduced to have one less double bond than SSq (compounds 2 and 14), so they were identified as dihydro-SSq or its isomer (such as 11,12dihydro-SSq, 13,18-dihydro-SSq, and other possible isomers); their possible structures are shown in Supplementary Figure S33.

Using the same approach, compound 41 was deduced to have one less double bond than Tibesaikosaponin I (compound 29), and combined with the maximum UV wavelength $(254 \mathrm{~nm})$, it was tentatively identified as $\Delta^{21,22}$-Tibesaikosaponin I; the structure is shown in Supplementary Figure S34. For compounds 29 and 94, it was speculated that their fragmentation pathways were similar to that of Tibesaikosaponin II, but there were no fragment ions produced by the loss of $30 \mathrm{Da}$, and thus, they were identified as Tibesaikosaponin I or its isomer (Fang et al., 2017), and presumably the $\mathrm{C}=\mathrm{O}$ group was conjugated with the adjacent olefinic bond, which stabilized the $\mathrm{C}=\mathrm{O}$ group and was not easy to lose; its fragmentation pathway is shown in Supplementary Figure S35.

Based on the analysis of the formulas, fragment ions, retention times, and maximum UV wavelengths, combined with a review of 
the literature, compound 21 was identified as Magnoside B (Haddad et al., 2012), and its fragmentation pathway is shown in Supplementary Figure S36. Compound 22 was identified as 3$O$-[ $\alpha$-L-Rhamnopyranosyl (1-4)- $\beta$-D-glucopyranosyl] oleanolic acid 28-O- $\beta$-D-glucopyranosyl ester (Achouri et al., 2017). Compounds 5 and 15 were identified as $(3 \beta, 21 \beta, 22 \alpha)-28$-[[2$O$-(6-Deoxy- $\alpha$-L-mannopyranosyl)- $\beta$-D-glucopyranosyl]oxy]21,22 -dihydroxyolean-12-en-3-yl 6-O- $\beta$-D-glucopyranosyl- $\beta$-Dglucopyranoside or its isomers (Xiao et al., 2013). Compound 68 was identified as $(3 \beta, 4 \alpha, 16 \alpha)$-3,16,23-trihydroxyoleanan-28-yl $O$ 6-deoxy- $\alpha$-L-mannopyranosyl-(1-4)-O-[ $\beta$-D-glucopyranosyl(1-6)]- $\beta$-D-glucopyranoside (Luo and Jin, 1991). Compound 95 was identified as Bupleuroside XI (Yoshikawa, 1997). All structures are shown in Supplementary Figure S37.

Characterization of Compounds 18, 36, 39, 43, 46, 53, $55,57,59,61-63,66,67,69,78,80-83,85,87-88$, 91-93, 98, 100-104, and 106-109 (Acetylated/ Malonylated Saikosaponins)

The mass spectra fragmentation information of the acetylated/ malonylated saikosaponins in the $\mathrm{ESI}^{+}$mode is shown in Supplementary Table S3. 35 acetylated/malonylated saikosaponins were identified in this study, including saikosaponin compounds compared with related standard substances.

Compounds 18, 53, 55, 57, 59, 61-63, 66-67, 69,78, 80-83, 85, $87-88,92-93,98,100,102-104$, and 109 all produced $[\mathrm{M}-42-\mathrm{H}]^{-}$and $[\mathrm{M}-60-\mathrm{H}]^{-}$fragment ions as diagnostic ions (Supplementary Datasheet S1); thus, they were identified as acetylated saikosaponins.

The compounds $81,87,88,92,55,62,66,102,103,104,109$, 78, 83, 93, and 98 were analyzed, and according to Supplementary Table S3, all fragment ions in the $\mathrm{ESI}^{+}$mode were $\mathrm{m} / \mathrm{z} 455\left(\left[\text { aglycone }-\mathrm{H}_{2} \mathrm{O}+\mathrm{H}\right]^{+}\right), \mathrm{m} / \mathrm{z} 437$ ([aglycone- $-2 \mathrm{H}_{2} \mathrm{O}$ $\left.+\mathrm{H}]^{+}\right)$, and $\mathrm{m} / \mathrm{z} 419\left(\left[\text { aglycone }-3 \mathrm{H}_{2} \mathrm{O}+\mathrm{H}\right]^{+}\right)$, indicating that their acetyl groups were all substituted by the saccharide chain. In the $\mathrm{ESI}^{-}$mode, in addition to $\mathrm{m} / \mathrm{z} 779\left([\mathrm{M}-42-\mathrm{H}]^{-}\right)$and $\mathrm{m} / \mathrm{z} 761$ $\left([\mathrm{M}-60-\mathrm{H}]^{-}\right)$, the remaining fragment ions of compounds 81,87 , 88 , and 92 were the same as those of SSa/SSd, and their retention times followed those of SSa but were before SSd; thus, they were identified as acetylated derivatives of SSa. For SSa, SSd, SSb $\mathrm{Sb}_{1}$, and $\mathrm{SSb}_{2}$, the $\mathrm{OH}$ group at the $1^{\prime \prime}$ position of the terminal glucose of the saccharide chain was attached to rhamnose, and only four $\mathrm{OH}$ groups at positions $2^{\prime \prime}, 3^{\prime \prime}, 4^{\prime \prime}$, and $6^{\prime \prime}$ were substituted by an acetyl group. Based on the order of their respective retention times, compounds $81,87,88$, and 92 were identified as $2^{\prime \prime}$-O-acetyl-SSa, $3^{\prime \prime}$-O-acetyl-SSa, $4^{\prime \prime}$-O-acetyl-SSa, and $6^{\prime \prime}$-O-acetyl-SSa, respectively. Of these, compounds 81 and 92 were confirmed by the standard substance. Similarly, the retention times of compounds 102, 103, 104, and 109 followed SSd, and compound 109 was $6^{\prime \prime}$-O-acetyl-SSd by comparison with the standard substance; according to the order of retention times, the compounds 102,103 , and 104 were inferred to be 2 "-O- acetyl-SSd, $3^{\prime \prime}$-O-acetyl-SSd, and $4^{\prime \prime}$-O-acetyl-SSd, respectively. For compounds $78,83,93,98$, and 100 , the abundance of the $\mathrm{m} / \mathrm{z}$ 423 fragment ion was smaller than that of the $\mathrm{m} / \mathrm{z} 439$ fragment ion, indicating that they were acetylated derivatives of $\mathrm{SSb}_{2}$. Combined with the order of their retention times, compounds
$78,83,98$, and 100 were $2^{\prime \prime}$-O-acetyl-SSb, $3^{\prime \prime}$-O-acetyl-SSb${ }_{2}, 4^{\prime \prime}-O$ acetyl-SSb$b_{2}$, and $6^{\prime \prime}-\mathrm{O}$-acetyl-SSb$b_{2}$, respectively. The abundance of the $\mathrm{m} / \mathrm{z} 423$ fragment ion of compound 93 was slightly higher than that of $\mathrm{m} / \mathrm{z} 439$, which indicated that it was an acetylated derivative of $\mathrm{SSb}_{1}\left(\mathrm{O}\right.$-acetyl-SSb$\left.b_{1}\right)$. The structures of these acetylated saikosaponins are shown in Supplementary Figure S38.

For compounds 53, 55, 62, and 66 in the $\mathrm{ESI}^{-}$mode, in addition to fragment ions such as $\mathrm{m} / \mathrm{z} 925\left([\mathrm{M}-42-\mathrm{H}]^{-}\right)$and $\mathrm{m} / \mathrm{z} 907$ $\left([\mathrm{M}-60-\mathrm{H}]^{-}\right)$, the other fragment ions were the same as those of SSc; thus, these were acetylated derivatives of SSc. Their fragment ions in the $\mathrm{ESI}^{+}$mode are shown in Supplementary Table S3 and in combination with the fragment ion in the $\mathrm{ESI}^{-}$mode $\mathrm{m} / \mathrm{z} 779$ $\left(\left[\mathrm{M}-42-\mathrm{C}_{6} \mathrm{H}_{10} \mathrm{O}_{4}-\mathrm{H}\right]^{-}\right)$and $\mathrm{m} / \mathrm{z} 761\left(\left[\mathrm{M}-60-\mathrm{C}_{6} \mathrm{H}_{10} \mathrm{O}_{4}-\mathrm{H}\right]^{-}\right)$, it was deduced that the acetyl group was substituted by the $\mathrm{OH}$ group of terminal glucose of the saccharide chain, rather than that of the aglycone. For SSc, the $\mathrm{OH}$ group at the $1^{\prime \prime \prime}$ position of the terminal glucose of the saccharide chain was attached to rhamnose, and only four $\mathrm{OH}$ groups at positions $2^{\prime \prime \prime}$, $3^{\prime \prime \prime}, 4^{\prime \prime \prime}$, and 6 " could be substituted by an acetyl group. Based on the order of their retention times, the 4 compounds were identified as $2^{\prime \prime \prime}-O$-acetyl-SSc, $3^{\prime \prime \prime}$-O-acetyl-SSc, $4^{\prime \prime \prime}-O$-acetylSSc, and $6^{\prime \prime \prime}-O$-acetyl-SSc, respectively. The fragmentation pathway in the $\mathrm{ESI}^{-}$mode for $6^{\prime \prime \prime}-\mathrm{O}$-acetyl-SSc is shown as a representative example in Supplementary Figure S39. Similarly, compounds 57, 59, 63, and 69 were identified as $2^{\prime \prime \prime}-O$-acetyl-SSf, $3^{\prime \prime \prime}$-O-acetyl-SSf, $\quad 4^{\prime \prime \prime}$-O-acetyl-SSf, and $6^{\prime \prime \prime}-O$ - acetyl-SSf, respectively. Their structures are shown in Supplementary Figure S40.

Based on the fragment ions, compounds $67,70,80$, and 85 were acetylated derivatives of $\mathrm{SSb}_{3} / \mathrm{SSb}_{4}$, and according to their fragment ions in the $\mathrm{ESI}^{+}$mode (Supplementary Table S3), their acetyl groups were substituted by saccharide chains. Of these, compound 67 had the shortest retention time, which was $2^{\prime \prime}-O$ acetyl- $\mathrm{SSb}_{3}$. After comparison with the standard substance, compound 80 was deduced to be 6 "I-O-acetyl-SSb$b_{3}$, while compound 85 had a retention time that followed that of compound 80 and was thus deduced to be $6^{\prime \prime}-\mathrm{O}$-acetyl-SSb $\mathrm{S}_{4}$; both structures are shown in Supplementary Figure S41.

The same analytical procedure was employed to identify compounds 36, 39, and 46 in the ESI mode, and the abundance of the $\mathrm{m} / \mathrm{z} 423$ ([aglycone-48-H] $]^{-}$) fragment ion was smaller than that of the fragment ion $\mathrm{m} / \mathrm{z} 439$ ([aglycone $-32-\mathrm{H}]^{-}$) for all compounds; thus, they were identified as acetylated derivatives of SSs $\left(\alpha-\mathrm{OH}\right.$ at position $\left.\mathrm{C}_{16}\right)$. Combined with their fragment ions in the $\mathrm{ESI}^{+}$mode (Supplementary Figure S28), the acetyl groups were all substituted by the terminal glucose of the saccharide chain. According to the order of the respective retention times, compounds 36, 39, and 46 were identified as three of $2^{\prime \prime \prime}-O$ acetyl-SSs, $3^{\prime \prime \prime}-O$-acetyl-SSs, $4^{\prime \prime \prime}-O$-acetyl-SSs, and $6^{\prime \prime \prime}-O$-acetylSSs, and the respective structures are shown in Supplementary Figure S42. With $6^{\prime \prime \prime}$-O-acetyl-SSs as a representative example, the fragmentation pathway in $\mathrm{ESI}^{-}$is shown in Supplementary Figure S43. Similarly, compound 18 was identified as $O$-acetylBupleuroside V. For compound 61, based on its formula and fragment ions in the $\mathrm{ESI}^{-}$mode, it was speculated that the $\mathrm{C}_{11}$ position had an additional $\mathrm{OCH}_{3}$ substituent at the aglycone 
compared with $\mathrm{O}$-acetyl-SSs, according to its fragment ion pattern in $\mathrm{ESI}^{+}$(Supplementary Table S3), which indicated that an acetyl group was substituted by the aglycone; it was identified as 23-O-acetyl-(11a-methoxyl-SSs), and its fragmentation pathway in the $\mathrm{ESI}^{-}$mode is shown in Supplementary Figure S44.

Compounds 106 and 108 were analyzed in $\mathrm{ESI}^{-}$, their fragment ions all appeared to be $\mathrm{m} / \mathrm{z} 821\left([\mathrm{M}-42-\mathrm{H}]^{-}\right), \mathrm{m} / \mathrm{z}$ $779\left([\mathrm{M}-84-\mathrm{H}]^{-}\right)$, and $\mathrm{m} / \mathrm{z} 761\left([\mathrm{M}-60-42-\mathrm{H}]^{-}\right)$, and the remaining fragment ions were the same as those of SSa/SSd, which indicated that they were diacetyl derivatization products of SSa/SSd. Supplementary Table S3 indicated that their acetyl groups were all substituted by the saccharide chain; according to their retention times, compounds 106 and 108 all followed the SSd; thus, they were identified as $O$-diacetyl-SSd.

For compounds 82 and 101 in the $\mathrm{ESI}^{-}$mode, $\mathrm{m} / \mathrm{z} 821$ $\left([\mathrm{M}-44-\mathrm{H}]^{-}\right)$and $\mathrm{m} / \mathrm{z} 779\left([\mathrm{M}-86-\mathrm{H}]^{-}\right)$fragment ions were produced, and the remaining fragment ions were the same as those of SSa/SSd, which indicated that they were malonylated derivatives of SSa/SSd. As shown in Supplementary Table S3, the malonyl groups were all substituted by the saccharide chain, and after assessing their retention time, compound 82 followed SSa and preceded SSd, and compound 101 followed SSd; thus, compound 82 was $O$-malonyl-SSa and compound 101 was $O$-malonyl-SSd. Similarly, compound 43 was identified as O-malony-hydroxysaikosaponin c.

Compounds 91 and 107 were analyzed in the $\mathrm{ESI}^{-}$mode, their fragment ions all appeared at $\mathrm{m} / \mathrm{z} 863\left([\mathrm{M}-44-\mathrm{H}]^{-}\right), \mathrm{m} / \mathrm{z} 821$ $\left([\mathrm{M}-86-\mathrm{H}]^{-}\right)$, and $\mathrm{m} / \mathrm{z} 779\left([\mathrm{M}-42-86-\mathrm{H}]^{-}\right)$, and the remaining fragment ions were the same as those of SSa/SSd, which indicated that their structures contained an additional malonyl substituent and an additional acetyl substituent compared with SSa/SSd. Supplementary Table S3 indicated that their malonyl and acetyl groups were substituted by the saccharide chain. Analyzing their retention times, compound 91 followed SSa and preceded SSd, and compound 107 followed SSd; thus, the former was O-malonylacetyl-SSa, and the latter was $O$-malonyl-acetyl-SSd.

\section{UPLC-PDA-Q/TOF-MS Analysis of the Saikosaponin Extract of BC and BMW}

The same sample processing and UPLC-PDA-Q/TOF-MS detection methods were applied to identify saikosaponins of $\mathrm{BC}$ and BMW, which were then compared with BMS, to explore the similarities and differences of saikosaponins from three Bupleurum species. As shown in Supplementary Figure S45, except for a few individual saikosaponins (compounds 15 and 96 were not found in BC, compounds 15, 83 and 96 were not found in BMW), the saikosaponins in BMS were almost the same as those in BC and BMW, which have a material basis as an alternative variety of $\mathrm{BC}$ and $\mathrm{BMW}$.

\section{DISCUSSION}

In this study, we used UPLC-PDA-Q/TOF-MS technology to identify saikosaponins from Bupleurum species. In previous studies on identification of saikosaponins by UPLC-MS, most of the sample-processing methods used organic reagents such as methanol to crudely extract the saikosaponins from samples, and the saikosaponin components were not further enriched and purified, which may cause omission and interference in the detection of saikosaponin components. In most studies, only a small amount of saikosaponin standards (0-12 standards) were used for analysis; the fragmentation pathways, characteristic loss, retention times, and UV spectral features of saikosaponin standards were not thoroughly analyzed and comprehensively summarized, so not only could some saikosaponins and their isomers not be accurately distinguished and structurally identified but also the types and numbers of saikosaponins identified in Bupleurum species were not many, usually dozens of them, and new saikosaponins are rarely found. Compared with previous studies on the identification of saikosaponins by UPLC-MS, the significance and advantages of our established method are summarized below. First, an effective sample-processing method was established, which not only purifies and enriches the saikosaponins but can also eliminate the interference of non-saikosaponins for subsequent analysis. Second, we combined DDA and DIA modes to complement each other and more accurately and comprehensively scanned and analyzed parent ions and product fragment ions of saikosaponins. Third, our study was the most comprehensive characterization of saikosaponins in Bupleurum species to date. In this study, the mass spectrometric fragmentation rules, UV spectral features, and chromatographic behaviors of different types of saikosaponins were first investigated and fully summarized using as many as 24 saikosaponin standard substances, the reliability of isomer structures was greatly improved, and a total of 109 saikosaponins were identified, of which 25 were new compounds. Fourth, this paper analyzed and summarized the characteristic fragment ions and fragmentation pathways of saikosaponins containing carbonyl groups and type IV saikosaponins for the first time, based on which these types of saikosaponins were identified, which is of great significance to the expansion of the identification of saikosaponin types.

\section{CONCLUSION}

Saikosaponins are the most important and prominent medicinal components in Bupleurum medicinal materials; thus, it is important to identify and analyze saikosaponins in BMS and other Bupleurum species. In this study, the fragmentation pathways of different types of saikosaponins were investigated by UPLC-PDA-Q/TOF-MS. Based on accurate exact mass and the elemental compositions of the fragment ions of 24 standard substances, the mass spectrometric fragmentation pathways, UV spectral features, and chromatographic behaviors were proposed and applied to identify the saikosaponins in extracts 
from BMS. A total of 109 saikosaponins were identified and characterized, of which 25 were new compounds and 60 were first discovered in BMS. Further studies revealed that the saikosaponins in BMS were almost the same as those in $\mathrm{BC}$ and $\mathrm{BMW}$, which indicates that there is a rationale for $\mathrm{BMS}$ to be used as an alternative to $\mathrm{BC}$ and BMW as medicine. This study provided a foundation for further quality control, pharmacological and pharmacodynamic studies, and the development and application of saikosaponins extracted from BMS and present in other Bupleurum species. In the future, we will also conduct detailed study regarding the remaining components of BMS, such as flavonoids, volatile oils, and polysaccharides.

\section{DATA AVAILABILITY STATEMENT}

The original contributions presented in the study are included in the article/Supplementary Material; further inquiries can be directed to the corresponding authors.

\section{REFERENCES}

Abe, H., Sakaguchi, M., Odashima, S., and Arichi, S. (1982). Protective Effect of Saikosaponin-D Isolated from Bupleurum Falcatum L. On CCl4Induced Liver Injury in the Rat. Naunyn-Schmiedeberg's Arch. Pharmacol. 320 (3), 266-271. doi:10.1007/BF00510139

Achouri, A., Derbré, S., Medjroubi, K., Laouer, H., Séraphin, D., and Akkal, S. (2017). Two New Triterpenoid Saponins from the Leaves of Bupleurum Lancifolium (Apiaceae). Nat. Product. Res. 31 (19), 2286-2293. doi:10.1080/ 14786419.2017.1324960

Ashour, M. L., and Wink, M. (2011). Genus Bupleurum: a Review of its Phytochemistry, Pharmacology and Modes of Action. J. Pharm. Pharmacol. 63 (3), 305-321. doi:10.1111/j.2042-7158.2010.01170.x

Barrero, A. F., Haidour, A., Sedqui, A., Mansour, A. I., Rodrı' guez-Garcı'a, I., López, A., et al. (2000). Saikosaponins from Roots of Bupleurum Gibraltaricum and Bupleurum Spinosum. Phytochemistry 54 (8), 741-745. doi:10.1016/s00319422(00)00177-1

Bateman, N. W., Goulding, S. P., Shulman, N. J., Gadok, A. K., Szumlinski, K. K., MacCoss, M. J., et al. (2014). Maximizing Peptide Identification Events in Proteomic Workflows Using Data-dependent Acquisition (DDA). Mol. Cell Proteom. 13 (1), 329-338. doi:10.1074/mcp.M112.026500

Cui, B.-S., Qiao, Y.-Q., Yuan, Y., Tang, L., Chen, H., Li, Y., et al. (2014). Hepatoprotective Saikosaponin Homologs from Comastoma Pedunculatum. Planta Med. 80 (17), 1647-1656. doi:10.1055/s-0034-1383123

Domon, B., and Costello, C. E. (1988). A Systematic Nomenclature for Carbohydrate Fragmentations in FAB-MS/MS Spectra of Glycoconjugates. Glycoconj. J. 5, 397-409. doi:10.1007/BF01049915

Ebata, N., Nakajima, K., Hayashi, K., Okada, M., and Maruno, M. (1996). Saponins from the Root of Bupleurum Falcatum. Phytochemistry 41 (3), 895-901. doi:10.1016/0031-9422(95)00720-2

Fang, W., Yang, Y.-J., Guo, B.-L., and Cen, S. (2017). Anti-influenza Triterpenoid Saponins (Saikosaponins) from the Roots of Bupleurum Marginatum Var. Stenophyllum. Bioorg. Med. Chem. Lett. 27 (8), 1654-1659. doi:10.1016/ j.bmcl.2017.03.015

Fujioka, T., Yoshida, K., Shibao, H., Nagao, T., Yoshida, M., Matsunaga, K., et al. (2006). Antiproliferative Constituents from Umbelliferae Plants. IX. New Triterpenoid Glycosides from the Fruits of Bupleurum Rotundifolium. Chem. Pharm. Bull. 54 (12), 1694-1704. doi:10.1248/cpb.54.1694

Guo, M. N., Liu, S. X., Zhao, Y. M., Zhang, T. J., and Liu, D. L. (2016). Analysis on Chemical Constituents in Bupleuri Radix by HPLC-Q-TOF-MS. Chin.

\section{AUTHOR CONTRIBUTIONS}

WL conceived, designed, and performed the experiments, analyzed the data, and wrote the manuscript. RK, XG, YW, and WJ assisted in performing the experiments. $\mathrm{XC}, \mathrm{FW}$, and $\mathrm{SM}$ revised the manuscript. All authors read and approved the manuscript.

\section{FUNDING}

This study was supported by grants from the project "Construction of Traditional Chinese Medicine Component Resource Database and Industrial Public Technology Service Platform" (No. 2018ZX09735-006) from the Important Program of Ministry of Science and Technology of the People's Republic of China.

\section{SUPPLEMENTARY MATERIAL}

The Supplementary Material for this article can be found online at: https://www.frontiersin.org/articles/10.3389/fchem.2021.747987/ full\#supplementary-material

Tradit. Herbal Drugs 47 (12), 2044-2052. doi:10.7501/j.issn.02532670.2016.12.005

Haddad, M., Lelamer, A., Moreno Y Banuls, L., Carraz, M., Vasquez, P., Vaisberg, A., et al. (2012). In Vitro growth Inhibitory Effects of 13, 28-epoxyoleanane Triterpene Saponins in Cancer Cells. Planta Med. 78 (11), PI179. doi:10.1055/s0032-1320867

Huang, H.-Q., Zhang, X., Lin, M., Shen, Y.-H., Yan, S.-K., and Zhang, W.-D. (2008). Characterization and Identification of Saikosaponins in Crude Extracts from threeBupleurumspecies Using LC-ESI-MS. J. Sep. Sci. 31 (18), 3190-3201. doi:10.1002/jssc.200800120

Jiang, H., Yang, L., Hou, A., Zhang, J., Wang, S., Man, W., et al. (2020). Botany, Traditional Uses, Phytochemistry, Analytical Methods, Processing, Pharmacology and Pharmacokinetics of Bupleuri Radix: A Systematic Review. Biomed. Pharmacother. 131, 110679. doi:10.1016/j.biopha.2020.110679

Law, K. P., and Lim, Y. P. (2013). Recent Advances in Mass Spectrometry: Data Independent Analysis and Hyper Reaction Monitoring. Expert Rev. Proteom. 10 (6), 551-566. doi:10.1586/14789450.2013.858022

Li, D.-Q., Wu, J., Liu, L.-Y., Wu, Y.-Y., Li, L.-Z., Huang, X.-X., et al. (2015). Cytotoxic Triterpenoid Glycosides (Saikosaponins) from the Roots of Bupleurum Chinense. Bioorg. Med. Chem. Lett. 25 (18), 3887-3892. doi:10.1016/j.bmcl.2015.07.053

Li, X., Li, X., Huang, N., Liu, R., and Sun, R. (2018). A Comprehensive Review and Perspectives on Pharmacology and Toxicology of Saikosaponins. Phytomedicine 50, 73-87. doi:10.1016/j.phymed.2018.09.174

Liang, Z., Oh, K., Wang, Y., Yi, T., Chen, H., and Zhao, Z. (2014). Cell Type-specific Qualitative and Quantitative Analysis of Saikosaponins in Three Bupleurum Species Using Laser Microdissection and Liquid Chromatography-Quadrupole/ time of Flight-Mass Spectrometry. J. Pharm. Biomed. Anal. 97, 157-165. doi:10.1016/j.jpba.2014.04.033

Liang, Z., Zhang, J., Yang, G., Chen, H., and Zhao, Z. (2013). Chemical Profiling and Histochemical Analysis of Bupleurum Marginatum Roots from Different Growing Areas of Hubei Province. Acta Pharm. Sin. B 3 (3), 193-204. doi:10.1016/j.apsb.2013.04.002

Liu, G., Zhang, Z., Lv, X., Zhan, S., Ding, B., Yang, X., et al. (2019). Localization of Malonyl and Acetyl on Substituted Saikosaponins According to the Full-scan Mass Spectra and the Fragmentation of Sodium-adduct Ions in the Positive Mode. Rapid Commun. Mass. Spectrom. 33 (9), 883-893. doi:10.1002/ rcm. 8415

Luo, S., and Jin, H. (1991). Studies on Chemical Constituents of Aboveground Parts of Six Medicinal Bupleurum Plants in Southwest China. Chin. Med. Mat 16 (6), 353-383. 
Miyase, T., and Matsushima, Y. (1997). Saikosaponin Homologues from Clinopodium Spp. The Structures of Clinoposaponins XII-XX. Chem. Pharm. Bull. 45 (9), 1493-1497. doi:10.1248/cpb.45.1493

Münger, L. H., Boulos, S., and Nyström, L. (2018). UPLC-MS/MS Based Identification of Dietary Steryl Glucosides by Investigation of Corresponding Free Sterols. Front. Chem. 6, 342. doi:10.3389/fchem.2018.00342

Qing, Z.-X., Zhao, H., Tang, Q., Mo, C.-m., Huang, P., Cheng, P., et al. (2017). Systematic Identification of Flavonols, Flavonol Glycosides, Triterpene and Siraitic Acid Glycosides from Siraitia Grosvenorii Using High-Performance Liquid Chromatography/quadrupole-Time-Of-Flight Mass Spectrometry Combined with a Screening Strategy. J. Pharm. Biomed. Anal. 138, 240-248. doi:10.1016/j.jpba.2017.01.059

Ren, M., McGowan, E., Li, Y., Zhu, X., Lu, X., Zhu, Z., et al. (2019). Saikosaponin-d Suppresses COX2 through p-STAT3/C/EBP $\beta$ Signaling Pathway in Liver Cancer: A Novel Mechanism of Action. Front. Pharmacol. 10, 623. doi:10.3389/fphar.2019.00623

Sánchez-Contreras, S., Díaz-Lanza, A. M., and Bernabé, M. (2000). Four New Triterpenoid Saponins from the Roots ofBupleurumrigidum. J. Nat. Prod. 63 (11), 1479-1482. doi:10.1021/np000004h

Shan, L., Yang, N., Zhao, Y., Sheng, X., Yang, S., and Li, Y. (2018). A Rapid Classification and Identification Method Applied to the Analysis of Glycosides in Bupleuri Radix and Liquorice by Ultra High Performance Liquid Chromatography Coupled with Quadrupole Time-Of-Flight Mass Spectrometry. J. Sep. Sci. 41 (19), 3791-3805. doi:10.1002/jssc.201800619

Sinha, S. K., Shakya, A., Prasad, S. K., Singh, S., Gurav, N. S., Prasad, R. S., et al. (2021). An In-Silico Evaluation of Different Saikosaponins for Their Potency against SARS-CoV-2 Using NSP15 and Fusion Spike Glycoprotein as Targets. J. Biomol. Struct. Dyn. 39 (9), 1-12. doi:10.1080/07391102.2020.1762741

Sun, P., Li, Y., Wei, S., Zhao, T., Wang, Y., Song, C., et al. (2018). Pharmacological Effects and Chemical Constituents of Bupleurum. Mrmc 19 (1), 34-55. doi:10.2174/1871520618666180628155931

Wang, H., Feng, M. L., Zhang, Y., Xi, X. H., Zhang, X. H., Song, M. Q., et al. (2020). Comparative Study on Acute Toxicity, Antipyretic and Anti-inflammatory Effects of Bupleurum MarginatumVar.Stenophyllum and Bupleurum. Modernization Tradit. Chin. Med. Materia Med. World Sci. Techn. 22 (05), 1517-1523. doi:10.11842/wst.20190512001

Wang, H., Feng, M. L., Zhang, Y., Xi, X. H., Zhang, X. H., Song, M. Q., et al. (2019). Protective Effect of Vinegar-Made Bupleurum Marginatum Var. Stenophyllum on Acute Liver Injury Induced by CCl4 in Mice. Cent. South Pharm. 10 (17), 1637-1641. doi:10.7539/j.issn.1672-2981.2019.10.010

Wang, X., Wang, Q., Burczynski, F. J., Kong, W., and Gong, Y. (2013). Saikosaponin A of Bupleurum Chinense (Chaihu) Elevates Bone Morphogenetic Protein 4 (BMP-4) during Hepatic Stellate Cell Activation. Phytomedicine 20 (14), 1330-1335. doi:10.1016/j.phymed.2013.07.010

Wang, Z., Liu, C.-H., Huang, S., and Chen, J. (2019). Wnt Signaling in Vascular Eye Diseases. Prog. Retin. Eye Res. 70 (20), 110-133. doi:10.1016/ j.preteyeres.2018.11.008

Xia, Z., Liu, X., Tong, L., Wang, H., Feng, M., Xi, X., et al. (2021). Comparison of Chemical Constituents of Bupleurum Marginatum Var. Stenophyllum and Bupleurum Chinense DC. Using UHPLC-Q-TOF-MS Based on a Metabonomics Approach. Biomed. Chromatogr. 35 (9), e5133. doi:10.1002/bmc.5133
Xiao, W., Wang, Y., Zhang, P., Li, N., Jiang, S., Wang, J.-h., et al. (2013). Bioactive Barrigenol Type Triterpenoids from the Leaves of Xanthoceras Sorbifolia Bunge. Eur. J. Med. Chem. 60, 263-270. doi:10.1016/ j.ejmech.2012.12.022

Yang, J.-B., Liu, Y., Wang, Q., Ma, S.-C., Wang, A.-G., Cheng, X.-L., et al. (2019). Characterization and Identification of the Chemical Constituents of Polygonum Multiflorum Thunb. By High-Performance Liquid Chromatography Coupled with Ultraviolet Detection and Linear Ion Trap FT-ICR Hybrid Mass Spectrometry. J. Pharm. Biomed. Anal. 172, 149-166. doi:10.1016/j.jpba.2019.03.049

Ye, Y. H., Shi, Y., Zhang, B. W., Chen, W. B., Ma, Y. N., and Yu, H. (2019). Fingerprint Analysis of Bupleurum Chinense Roots from Different Origins by UPLC/Q-TOF-MS. Chin. J. Exp. Tradit Med. Form 25 (18), 124-129. doi:10.13422/j.cnki.syfjx.20190748

Yoshikawa, I. M. (1997). New Hepatoprotective Saponins, Bupleurosides Iii, Vi, Ix, and Xiii, from Chinese Bupleuri Radix: Structure-Requirements for the Cytoprotective Activity in Primary Cultured Rat Hepatocytes. Bioorg. Med. Chem. Lett. 7, 2193. doi:10.1016/S0960-894X(97)00418-6

Yu, J.-Q., Deng, A.-J., and Qin, H.-L. (2014). Distinctive Features of Chemical Composition of Bupleurum Chinense Applicable to Original Authentication. Anal. Methods 25 (18), 1067-1075. doi:10.1039/c3ay41530a

Yu, J.-Q., Deng, A.-J., Wu, L.-Q., Zhang, Z.-H., Liu, Y., Wang, W.-J., et al. (2013). Osteoclast-inhibiting Saikosaponin Derivatives from Bupleurum Chinense. Fitoterapia 85, 101-108. doi:10.1016/j.fitote.2013.01.005

Zhao, X., Liu, J., Ge, S., Chen, C., Li, S., Wu, X., et al. (2019). Saikosaponin A Inhibits Breast Cancer by Regulating Th1/Th2 Balance. Front. Pharmacol. 10, 624. doi:10.3389/fphar.2019.00624

Zhao, Y.-y., Luo, H.-s., Wang, B., Ma, L.-b., Tu, G.-z., and Zhang, R.-y. (1996). Triterpenoid Saponins from Bupleurum Smithii Var. Parvifolium. Phytochemistry 42 (6), 1673-1675. doi:10.1016/0031-9422(96)00026-x

Zhu, Y.-D., Hong, J.-Y., Bao, F.-D., Xing, N., Wang, L.-T., Sun, Z.-H., et al. (2018). Triterpenoid Saponins from Clinopodium Chinense (Benth.) O. Kuntze and Their Biological Activity. Arch. Pharm. Res. 41 (12), 1117-1130. doi:10.1007/ s12272-017-0943-9

Conflict of Interest: The authors declare that the research was conducted in the absence of any commercial or financial relationships that could be construed as a potential conflict of interest.

Publisher's Note: All claims expressed in this article are solely those of the authors and do not necessarily represent those of their affiliated organizations, or those of the publisher, the editors, and the reviewers. Any product that may be evaluated in this article, or claim that may be made by its manufacturer, is not guaranteed or endorsed by the publisher.

Copyright $\odot 2021$ Liu, Cheng, Kang, Wang, Guo, Jing, Wei and Ma. This is an openaccess article distributed under the terms of the Creative Commons Attribution License (CC BY). The use, distribution or reproduction in other forums is permitted, provided the original author(s) and the copyright owner(s) are credited and that the original publication in this journal is cited, in accordance with accepted academic practice. No use, distribution or reproduction is permitted which does not comply with these terms. 